\title{
Analysis of three-dimensional transient seepage into ditch drains from a ponded field
}

\author{
RATAN SARMAH $^{1, *}$ and GAUTAM BARUA ${ }^{2}$ \\ ${ }^{1}$ Department of Civil Engineering, National Institute of Technology Meghalaya, Shillong 793003, India \\ ${ }^{2}$ Department of Civil Engineering, Indian Institute of Technology Guwahati, Guwahati 781039, India \\ e-mail: ratan@nitm.ac.in; g_barua@iitg.ernet.in
}

MS received 4 April 2016; revised 19 September 2016; accepted 7 October 2016

\begin{abstract}
An analytical solution in the form of infinite series is developed for predicting time-dependent three-dimensional seepage into ditch drains from a flat, homogeneous and anisotropic ponded field of finite size, the field being assumed to be surrounded on all its vertical faces by ditch drains with unequal water level heights in them. It is also assumed that the field is being underlain by a horizontal impervious barrier at a finite distance from the surface of the soil and that all the ditches are being dug all the way up to this barrier. The solution can account for a variable ponding distribution at the surface of the field. The correctness of the proposed solution for a few simplified situations is tested by comparing predictions obtained from it with the corresponding values attained from the analytical and experimental works of others. Further, a numerical check on it is also performed using the Processing MODFLOW environment. It is noticed that considerable improvement on the uniformity of the distribution of the flow lines in a three-dimensional ponded drainage space can be achieved by suitably altering the ponding distribution at the surface of the soil. As the developed three-dimensional ditch drainage model is pretty general in nature and includes most of the common variables of a ditch drainage system, it is hoped that the drainage designs based on it for reclaiming salt-affected and water-logged soils would prove to be more efficient and cost-effective as compared with designs based on solutions developed by making use of more restrictive assumptions. Also, as the developed model can handle three-dimensional flow situations, it is expected to provide reliable and realistic drainage solutions to real field situations than models being developed utilizing the two-dimensional flow assumption. This is because the existing two-dimensional solutions to the problem are actually valid not for a field of finite size but for an infinite one only.
\end{abstract}

Keywords. Analytical models; three-dimensional ponded ditch drainage; transient seepage; variable ponding; hydraulic conductivity; specific storage.

\section{Introduction}

Subsurface drainage as a means of combating waterlogging and salinity in irrigated lands has been a standard practice for quite some time now [1-3]. Irrigation is a necessity in many arid and semi-arid regions for augmenting agricultural productivity $[4,5]$ but this practice has resulted in reducing vast tracks of agricultural land to saline and waterlogged soils in many regions of the world, including India [2, 6-9]- to name a few). The salts present in a soil column may be washed by forcing good quality irrigation water through it and then draining the salt laden water via subsurface drains [10-14]. Subsurface drains are now also playing an increasingly important role in reducing the emission of the greenhouse gas methane from paddy fields $[15,16]$. Also, since subsurface flow to a stream or a river from the surroundings under a given hydro-geological

*For correspondence situation is similar to that of the flow to a ditch drain under the same setting [17], subsurface drainage studies associated with a ditch drainage system should then be also useful in analysing groundwater flow behaviour to a stream or river under similar hydro-geological settings as well. Thus, it is clear that subsurface drainage studies have multiple uses and hence efforts need be directed to understand in detail the hydraulics of flow associated with such a system.

This study will be focused on investigating the transient hydraulics of flow associated with a three-dimensional ponded ditch drainage system. Several steady-state theories were proposed in the past defining steady two-dimensional seepage of water into ditch drains from a continuously ponded field under different hydro-geological settings [3, 12, 18-32]. Extensive reviews of most of these twodimensional steady state solutions were given by Barua and Alam [10], Afruzi et al [28] and Sarmah and Barua [12]. Barua and Alam [10] provided an analytical solution for predicting two-dimensional seepage into a network of 
equally spaced ditch drains from a ponded field underlain by an impervious barrier. This solution assumes the ditch drains to penetrate all the way up to the impervious. A notable feature of this solution is that it can account for a variable ponding field at the surface of the soil. Xin et al [13] utilized the SUTRA [33] finite-element codes to study the effect of macro-pores in a continuously ponded subsurface drainage system by performing 3-D steady-state simulations. Their study shows that the macro-pores inhabit infiltration and hence decrease the leaching efficiency of a ponded ditch drainage system.

Drainage from a uniformly ponded field is mostly confined to areas close to the drains with very little water movement taking place in locations further away from the drains; this has been the conclusion of many drainage studies [3, 10-12, 14, 18, 20, 23, 28, 29, 32, 34-36]-to name only a few) of the past related to ponded drainage, irrespective of whether drainage is being carried out using tile or ditch drains. Thus, it is a challenge to leach a saltaffected soil in a uniform way using a conventional constant-depth ponded ditch drainage system since, under such a system, the areas in the immediate vicinity of the drains get over-washed and the areas away from the drains underwashed. The uniformity of leaching of a soil column via a ponded drainage system can be improved by washing it in stages and subjecting the same to a sequential and/or fractional ponding distribution at its surface [11, 14, 36]. However, instead of carrying out the leaching in stages, subjecting the soil surface to a progressively increasing ponding field away from the centre of the ditches to midway between the drains may also lead to a good uniformity of leaching of the soil profile. The main advantage of this method is that the entire leaching procedure can be carried out in a single step. The analytical works of Barua and Alam [10] and Barua and Sarmah [29] provide a way to work out the surface water ponding distribution required specific to a leaching scenario for achieving a relatively uniform cleaning of the soil profile via a ditch drainage ponded system.

All the analytical solutions as mentioned earlier for the ponded ditch drainage problem are based on the assumption of two-dimensional flow in the drainage space. Thus, all these solutions assume that the flow to the drains from a ponded field is restricted to a vertical plane only orthogonal to the drains, an assumption that intrinsically means that the horizontal ponded field supplying water to the drains is of an infinite size and that the drains removing water from the field are also of infinite length. The finite-element modelling studies of Brainard and Gelhar [17] (see also Murdoch [37] and Meigs and Bahr [38]) on subsurface flow to a straight stream of finite length due to a steady recharge in the surrounding soil, however, clearly demonstrate that flow in such a situation is mostly three-dimensional in nature, particularly if the anisotropy ratio of the soil is high. Thus, two-dimensional vertical section models may not be the best ones for analysing subsurface flow behaviour near streams and ditches and three-dimensional models may be the most appropriate ones to study such situations. As mentioned earlier, mid-season drainage of paddy fields is proving to be increasingly helpful in bringing about a reduction in the emission of the greenhouse gas methane from these fields; drainage also helps in providing a desirable soil-air-water ambience in the root zone of paddies. The size of the paddy plots in the Southeast Asian countries, in general, is much smaller than that of USA and Australia [39]. Hence, from what has been said before, subsurface drainage from these ponded fields to surrounding open drains is expected to be mainly three-dimensional in nature. In view of the same, an effort is being made here to obtain an analytical solution for predicting transient three-dimensional seepage from a finite-sized ponded field to adjacent drains. It is hoped that this solution will lead to better designs of open drains for reclaiming saline and surface waterlogged soils as compared to designs based on solutions derived with the two-dimensional flow assumption. This is because, unlike a three-dimensional solution of a drainage problem, which is valid for a field of finite size, a drainage solution developed with the two-dimensional flow assumption is actually valid (strictly speaking) for an infinite-sized field only. Also, as subsurface flow to an open ditch is similar to flow to a river or stream under identical conditions, the proposed model is also expected to be helpful in studying subsurface flow behaviour to a river or stream when the surroundings get inundated with flood water. It may also be used to check the convergence of complex numerical codes involving three-dimensional seepage to drains and rivers after reducing these codes to the relatively simpler settings for which solutions have been obtained in the present study. As an analytical solution helps in providing a physical insight into a hydro-system, it is hoped that the model proposed here would also lead to having a better understanding of the interplay of various parameters associated with the hydraulics of a three-dimensional ditch drainage system.

\section{Mathematical formulation and solution}

The geometry of the flow problem considered for study is as shown in figure 1. A finitely sized horizontal soil column of surface area $L \times B$ and thickness $h$ is being drained by four ditch drains placed on the four sides of the soil column, the soil being imposed with a variable ponding field at its surface and is being underlain by an impervious barrier. A coordinate system as shown in the figure is imposed into the system with the $x$-axis measuring positive towards the Eastern boundary, $y$-axis measuring positive towards the Northern boundary and $z$-axis positive measuring vertically downwards towards the impervious barrier. The water level heights on the North, South, East and West boundary drains are taken as $H_{1}, H_{2}, H_{3}$ and $H_{4}$, respectively, all these 

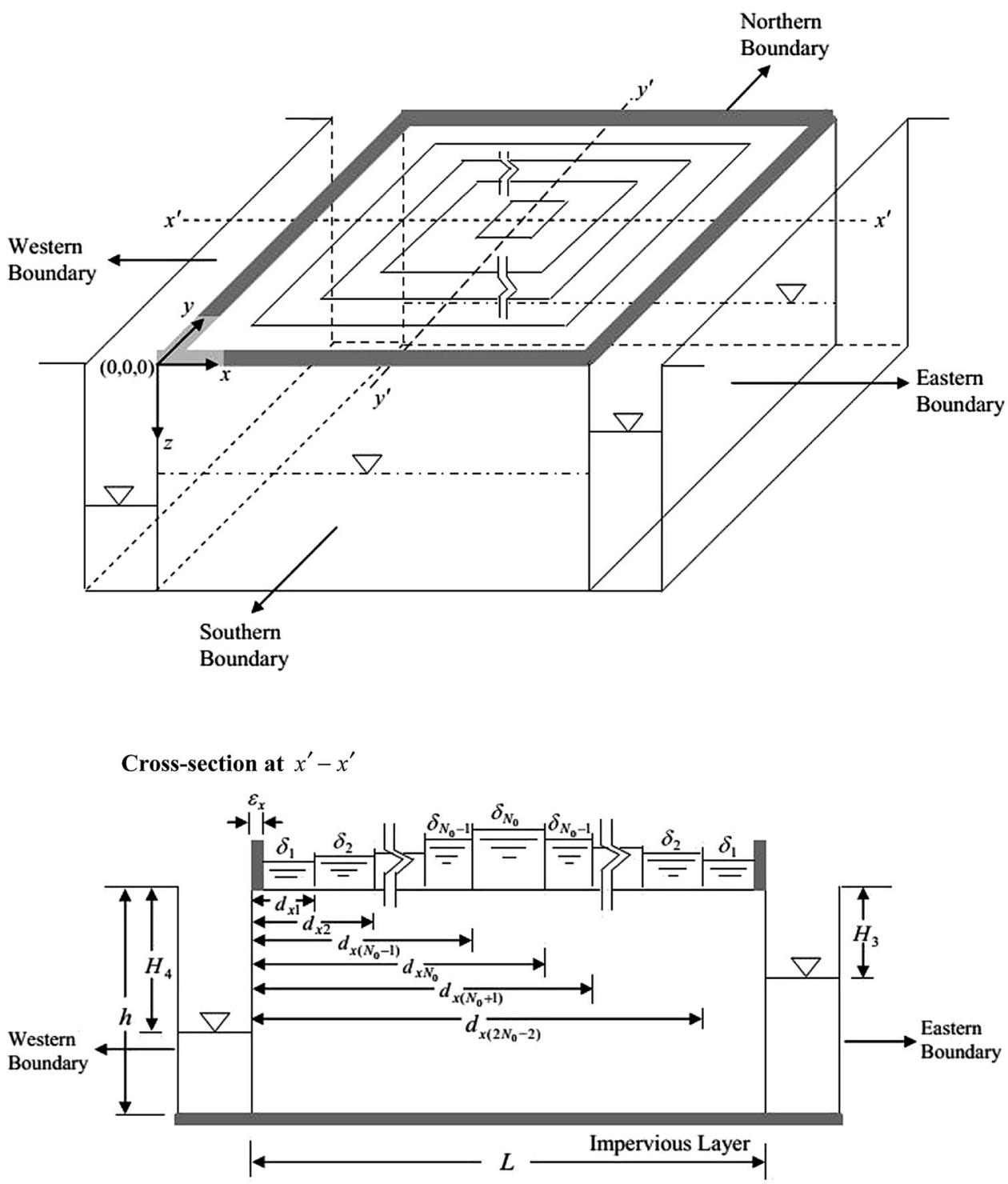

Cross-section at $y^{\prime}-y^{\prime}$

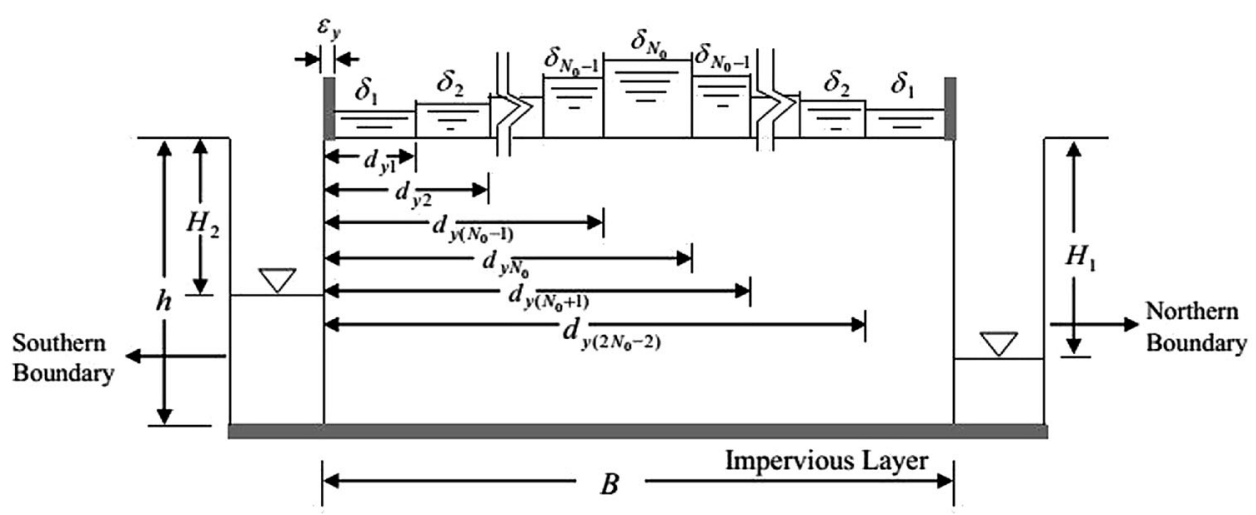

Figure 1. Geometry and sectional views of a three-dimensional ditch drainage system subjected to a variable ponding distribution at the surface of the soil, the soil being flanked on four of its sides by ditch drains with specified water level depths in them. 
distances being measured from the origin $O$, as can be observed in the sectional views of the flow problem. The unequal water level heights in the ditches can be maintained with the help of adjustable gates and weirs with different weir heights. The water level height of the collecting drain(s) should be lower than the lowest water level height of the four surrounding drains (i.e., North, South, East and West boundary drains). The ponding pyramid of $N_{0}$ depths at the surface of the soil is being introduced by constructing $N_{0}$ ponding strips with the help of bunds and the ponding depth at the $i$ th strip is denoted as $\delta_{i}$ $\left(1 \leq i \leq N_{0}\right)$. Ditch bunds of width $\varepsilon_{x}$ and $\varepsilon_{y}$ are provided along the edges of the ditches so as to prevent the ponding water from flowing directly to the ditches; these bunds, however, for simplicity like in Kirkham [19, 20], are assumed to be impervious and of negligible size in the mathematical treatment. It should be noted that for a ponded soil column having a uniform and negligible ponding depth over it, the side bunds are not really required as in such a situation the water will not roll over directly to the ditches from the surface of the soil.

The distance of the $i$ th bund, as measured from the origin $O$, in the $x$ - and $y$ - directions are taken as $d_{x i}$ and $d_{y i}\left[1 \leq i \leq 2\left(N_{0}-1\right) ; N_{0}>1\right]$, respectively. It should be noted that for $N_{0}=1$, there will be no inner bunds on the surface of the soil and the ponding depth will then be a uniform one. For mathematical simplicity, like the side bunds, the widths of the inner bunds are also assumed to be of negligible size (i.e., they are considered as infinitesimals). The directional conductivities of the soil column along the $x$-, $y$ - and $z$-directions are taken as $K_{x}, K_{y}$ and $K_{z}$, respectively and $S_{s}$ denotes the specific storage of the soil column. For an isotropic soil, the hydraulic conductivity will be the same in all the three directions; the conductivity of such a soil is denoted here as $K$. The ponding depths in between the bunds are assumed to be non-changing with time and the soil is assumed to be fully saturated. The constancy of the ponding depths in the ponding strips can be maintained by constantly feeding the surface of the soil with irrigation water; that way, the loss of water to the soil due to infiltration can be balanced at all times. Additionally, it is also supposed that the ponding distribution at the surface and the water level in the ditches are inputted instantaneously into the system, the water previously been assumed to be standing flash with the saturated horizontal field. With the above assumptions and nomenclature in place and further, naming the hydraulic head function as $\phi$ and the time variable as $t$, the initial and boundary conditions for the three-dimensional flow problem of figure 1 can be expressed as

$$
\phi(x, y, z, t=0)=0, \quad 0<x<L, \quad 0<y<B, \quad 0<z<h,
$$

$$
\begin{aligned}
& \phi(x, y, z, t>0)=-z, \quad 0<x<L, \quad y=B, \quad 0<z<H_{1}, \\
& \phi(x, y, z, t>0)=-z, \quad 0<x<L, \quad y=0, \quad 0<z<H_{2}, \\
& \phi(x, y, z, t>0)=-z, \quad x=L, \quad 0<y<B, \quad 0<z<H_{3}, \\
& \phi(x, y, z, t>0)=-H_{3}, \quad x=L, \quad 0<y<B, \quad H_{3} \leq z<h, \\
& \phi(x, y, z, t>0)=-z, \quad x=0, \quad 0<y<B, \quad 0<z<H_{4},
\end{aligned}
$$

$\phi(x, y, z, t>0)=-H_{4}, \quad x=0, \quad 0<y<B, \quad H_{4} \leq z<h$,

$$
\frac{\partial \phi(x, y, z, t>0)}{\partial z}=0, \quad 0<x<L, \quad 0<y<B, \quad z=h,
$$

$\phi(x, y, z, t>0)=\delta_{1}, \quad 0<x<L, \quad 0<y<d_{y 1}, \quad z=0$,

$$
\begin{aligned}
& \phi(x, y, z, t>0)=\delta_{1}, \quad 0<x<L, \quad d_{y\left(2 N_{0}-2\right)}<y<B, \\
& \quad z=0
\end{aligned}
$$

$\phi(x, y, z, t>0)=\delta_{1}, \quad 0<x<d_{x 1}, \quad d_{y 1}<y<d_{y\left(2 N_{0}-2\right)}, \quad z=0$,

$$
\begin{gathered}
\phi(x, y, z, t>0)=\delta_{1}, \quad d_{x\left(2 N_{0}-2\right)}<x<L, \\
d_{y 1}<y<d_{y\left(2 N_{0}-2\right)}, \quad z=0,
\end{gathered}
$$

$$
\begin{gathered}
\phi(x, y, z, t>0)=\delta_{j}, \quad d_{x(j-1)}<x<d_{x\left(2 N_{0}-j\right)}, \\
d_{y(j-1)}<y<d_{y j}, \quad z=0,
\end{gathered}
$$

$$
\begin{gathered}
\phi(x, y, z, t>0)=\delta_{j}, \quad d_{x(j-1)}<x<d_{x\left(2 N_{0}-j\right)}, \\
d_{y\left(2 N_{0}-j-1\right)}<y<d_{y\left(2 N_{0}-j\right)}, \quad z=0,
\end{gathered}
$$$$
\phi(x, y, z, t>0)=\delta_{j}, \quad d_{x(j-1)}<x<d_{x j},
$$$$
d_{y j}<y<d_{y\left(2 N_{0}-j-1\right)}, \quad z=0,
$$

$$
\begin{gathered}
\phi(x, y, z, t>0)=\delta_{j}, \quad d_{x\left(2 N_{0}-j-1\right)}<x<d_{x\left(2 N_{0}-j\right)}, \\
d_{y j}<y<d_{y\left(2 N_{0}-j-1\right)}, \quad z=0
\end{gathered}
$$




$$
\begin{gathered}
\phi(x, y, z, t>0)=\delta_{N_{0}}, \quad d_{x\left(N_{0}-1\right)}<x<d_{x N_{0}}, \\
d_{y\left(N_{0}-1\right)}<y<d_{y N_{0}}, \quad z=0,
\end{gathered}
$$

where $2 \leq j \leq N_{0}-1$.

It is now proposed to obtain an analytical solution to the equation governing three-dimensional transient groundwater flow in a saturated, homogeneous, anisotropic and compressible soil subject to the above boundary and initial conditions. For such a soil, the governing equation of groundwater flow can be expressed as [40]

$$
K_{x} \frac{\partial^{2} \phi}{\partial x^{2}}+K_{y} \frac{\partial^{2} \phi}{\partial y^{2}}+K_{z} \frac{\partial^{2} \phi}{\partial z^{2}}=S_{s} \frac{\partial \phi}{\partial t}
$$

where the symbols pertaining to Eq. (1) have already been defined. Falling on the separation of variable method [41], a solution of Eq. (1) can be expressed as [42]

$$
Y=\left(\sqrt{\frac{K_{z}}{K_{y}}}\right) y=\frac{y}{K_{y}^{a}},
$$

$$
N_{n_{1}}=\left[\left(\frac{1-2 n_{1}}{2}\right) \frac{\pi}{h}\right]
$$

$$
\begin{aligned}
\phi(X, Y, z, t)= & \sum_{m_{1}=1}^{M_{1}} \sum_{n_{1}=1}^{N_{1}} A_{m_{1} n_{1}} \frac{\sinh \left[\sqrt{\left(N_{m_{1}}\right)^{2}+\left(N_{n_{1}}\right)^{2}}\left(B_{Y}-Y\right)\right]}{\sinh \left[\sqrt{\left(N_{m_{1}}\right)^{2}+\left(N_{n_{1}}\right)^{2}} B_{Y}\right]} \sin \left(N_{m_{1}} X\right) \sin \left(N_{n_{1}} z\right) \\
& +\sum_{m_{2}=1}^{M_{2}} \sum_{n_{2}=1}^{N_{2}} B_{m_{2} n_{2}} \frac{\sinh \left[\sqrt{\left(N_{m_{2}}\right)^{2}+\left(N_{n_{2}}\right)^{2}} Y\right]}{\sinh \left[\sqrt{\left(N_{m_{2}}\right)^{2}+\left(N_{n_{2}}\right)^{2}} B_{Y}\right]} \sin \left(N_{m_{2}} X\right) \sin \left(N_{n_{2}} z\right) \\
& +\sum_{m_{3}=1}^{M_{3}} \sum_{n_{3}=1}^{N_{3}} C_{m_{3} n_{3}} \frac{\sinh \left[\sqrt{\left(N_{m_{3}}\right)^{2}+\left(N_{n_{3}}\right)^{2}}\left(L_{X}-X\right)\right]}{\sinh \left[\sqrt{\left(N_{m_{3}}\right)^{2}+\left(N_{n_{3}}\right)^{2}} L_{X}\right]} \sin \left(N_{m_{3}} Y\right) \sin \left(N_{n_{3}} z\right) \\
& +\sum_{m_{4}=1}^{M_{4}} \sum_{n_{4}=1}^{N_{4}} D_{m_{4} n_{4}} \frac{\sinh \left[\sqrt{\left(N_{m_{4}}\right)^{2}+\left(N_{n_{4}}\right)^{2}} X\right]}{\sinh \left[\sqrt{\left(N_{m_{4}}\right)^{2}+\left(N_{n_{4}}\right)^{2}} L_{X}\right]} \sin \left(N_{m_{4}} Y\right) \sin \left(N_{n_{4}} z\right) \\
& +\sum_{m_{5}=1}^{M_{5}} \sum_{n_{5}=1}^{N_{5}} F_{m_{5} n_{5}} \frac{\cosh \left[\sqrt{\left(N_{m_{5}}\right)^{2}+\left(N_{n_{5}}\right)^{2}}(h-z)\right]}{\cosh \left[\sqrt{\left(N_{m_{5}}\right)^{2}+\left(N_{n_{5}}\right)^{2}} h\right]} \sin \left(N_{m_{5}} X\right) \sin \left(N_{n_{5}} Y\right) \\
& +\sum_{p=1}^{P} \sum_{q=1}^{Q} \sum_{r=1}^{R} E_{p q r} \sin \left(N_{p} X\right) \sin \left(N_{q} Y\right) \sin \left(N_{r} z\right) \exp \left[-\frac{\left(\lambda_{p q r}\right)^{2} t}{\left.\left(K_{1}\right)^{2}\right]}\right.
\end{aligned}
$$

where

$$
\begin{gathered}
\left(K_{x}^{a}\right)^{2}=\frac{K_{x}}{K_{z}}, \\
\left(K_{y}^{a}\right)^{2}=\frac{K_{y}}{K_{z}}, \\
X=\left(\sqrt{\frac{K_{z}}{K_{x}}}\right) x=\frac{x}{K_{x}^{a}},
\end{gathered}
$$

$$
\begin{gathered}
N_{m_{2}}=\frac{m_{2} \pi}{L_{X}}, \\
N_{n_{2}}=\left[\left(\frac{1-2 n_{2}}{2}\right) \frac{\pi}{h}\right], \\
N_{m_{3}}=\frac{m_{3} \pi}{B_{Y}}, \\
N_{n_{3}}=\left[\left(\frac{1-2 n_{3}}{2}\right) \frac{\pi}{h}\right],
\end{gathered}
$$




$$
\begin{gathered}
N_{m_{4}}=\frac{m_{4} \pi}{B_{Y}} \\
N_{n_{4}}=\left[\left(\frac{1-2 n_{4}}{2}\right) \frac{\pi}{h}\right], \\
N_{m_{5}}=\frac{m_{5} \pi}{L_{X}}, \\
N_{n_{5}}=\frac{n_{5} \pi}{B_{Y}}, \\
N_{p}=\frac{p \pi}{L_{X}}, \\
N_{q}=\frac{q \pi}{B_{Y}}, \\
N_{r}=\left[\left(\frac{1-2 r}{2}\right) \frac{\pi}{h}\right], \\
\left(\lambda_{p q r}\right)^{2}=\left(N_{p}\right)^{2}+\left(N_{q}\right)^{2}+\left(N_{r}\right)^{2}, \\
\left(K_{1}\right)^{2}=\left(\frac{S_{s}}{K_{z}}\right)
\end{gathered}
$$

$M_{1}, N_{1}, M_{2}, N_{2}, M_{3}, N_{3}, M_{4}, N_{4}, M_{5}, N_{5}, P, Q$ and $R$ are all integers tending to infinity and $A_{m_{1} n_{1}}, B_{m_{2} n_{2}}, C_{m_{3} n_{3}}$, $D_{m_{4} n_{4}}, F_{m_{5} n_{5}}$ and $E_{p q r}$ are constants to be determined using the relevant boundary and initial conditions. It is worth noting here that Eq. (2), by its very definition, satisfies boundary condition (VI). Appendix 1 provides the complete procedure of determining these constants utilizing the initial and boundary conditions. Once these constants are determined, the velocity distributions in the $x$-, $y$ - and $z$ directions, $V_{x}, V_{y}$ and $V_{z}$, in the drainage space can next be worked out by applying the Darcy's law to the hydraulic head expression (after first converting it to the real space by making use of Eqs. (5) and (6)) of Eq. (2); the relevant expressions for the same are

$$
\begin{aligned}
& V_{x}(x, y, z, t)=-K_{x} \frac{\partial \phi}{\partial x} \\
& V_{y}(x, y, z, t)=-K_{y} \frac{\partial \phi}{\partial y}
\end{aligned}
$$

and

$$
V_{z}(x, y, z, t)=-K_{z} \frac{\partial \phi}{\partial z}
$$

In the same way, Darcy's law can be applied to evaluate the top discharge function, $Q_{\text {top }}^{f}$, at the surface of the soil; thus, $Q_{\text {top }}^{f}$ can be represented as follows:

$$
\begin{aligned}
& Q_{\mathrm{top}}^{f}(x, y, t)=-K_{z} \int_{\varepsilon_{x}}^{x} \int_{\varepsilon_{y}}^{y}\left(\frac{\partial \phi}{\partial z}\right) d x d y \\
& =-K_{z}\left\{\sum_{m_{1}=1}^{M_{1}} \sum_{n_{1}=1}^{N_{1}} A_{m_{1} n_{1}}\left(\frac{K_{x}^{a} K_{y}^{a} N_{n_{1}}}{N_{m_{1}}}\right)\left[\cos \left(\frac{N_{m_{1}} \varepsilon_{x}}{K_{x}^{a}}\right)-\cos \left(\frac{N_{m_{1}} x}{K_{x}^{a}}\right)\right]\right. \\
& \times \frac{\cosh \left[\sqrt{\left(N_{m_{1}}\right)^{2}+\left(N_{n_{1}}\right)^{2}}\left(\frac{B-\varepsilon_{y}}{K_{y}^{a}}\right)\right]-\cosh \left[\sqrt{\left(N_{m_{1}}\right)^{2}+\left(N_{n_{1}}\right)^{2}}\left(\frac{B-y}{K_{y}^{a}}\right)\right]}{\sinh \left[\sqrt{\left(N_{m_{1}}\right)^{2}+\left(N_{n_{1}}\right)^{2}}\left(\frac{B}{K_{y}^{a}}\right)\right] \sqrt{\left(N_{m_{1}}\right)^{2}+\left(N_{n_{1}}\right)^{2}}} \\
& +\sum_{m_{2}=1}^{M_{2}} \sum_{n_{2}=1}^{N_{2}} B_{m_{2} n_{2}}\left(\frac{K_{x}^{a} K_{y}^{a} N_{n_{2}}}{N_{m_{2}}}\right)\left[\cos \left(\frac{N_{m_{2}} \varepsilon_{x}}{K_{x}^{a}}\right)-\cos \left(\frac{N_{m_{2}} x}{K_{x}^{a}}\right)\right] \\
& \times \frac{\cosh \left[\sqrt{\left(N_{m_{2}}\right)^{2}+\left(N_{n_{2}}\right)^{2}}\left(\frac{y}{K_{y}^{a}}\right)\right]-\cosh \left[\sqrt{\left(N_{m_{2}}\right)^{2}+\left(N_{n_{2}}\right)^{2}}\left(\frac{\varepsilon_{y}}{K_{y}^{a}}\right)\right]}{\sinh \left[\sqrt{\left(N_{m_{2}}\right)^{2}+\left(N_{n_{2}}\right)^{2}}\left(\frac{B}{K_{y}^{a}}\right)\right] \sqrt{\left(N_{m_{2}}\right)^{2}+\left(N_{n_{2}}\right)^{2}}} \\
& +\sum_{m_{3}=1}^{M_{3}} \sum_{n_{3}=1}^{N_{3}} C_{m_{3} n_{3}}\left(\frac{K_{x}^{a} K_{y}^{a} N_{n_{3}}}{N_{m_{3}}}\right)\left[\cos \left(\frac{N_{m_{3}} \varepsilon_{y}}{K_{y}^{a}}\right)-\cos \left(\frac{N_{m_{3}} y}{K_{y}^{a}}\right)\right] \\
& \times \frac{\cosh \left[\sqrt{\left(N_{m_{3}}\right)^{2}+\left(N_{n_{3}}\right)^{2}}\left(\frac{L-\varepsilon_{x}}{K_{x}^{x}}\right)\right]-\cosh \left[\sqrt{\left(N_{m_{3}}\right)^{2}+\left(N_{n_{3}}\right)^{2}}\left(\frac{L-x}{K_{x}^{a}}\right)\right]}{\sinh \left[\sqrt{\left(N_{m_{3}}\right)^{2}+\left(N_{n_{3}}\right)^{2}}\left(\frac{L}{K_{x}^{a}}\right)\right] \sqrt{\left(N_{m_{3}}\right)^{2}+\left(N_{n_{3}}\right)^{2}}} \\
& +\sum_{m_{4}=1}^{M_{4}} \sum_{n_{4}=1}^{N_{4}} D_{m_{4} n_{4}}\left(\frac{K_{x}^{a} K_{y}^{a} N_{n_{4}}}{N_{m_{4}}}\right)\left[\cos \left(\frac{N_{m_{4}} \varepsilon_{y}}{K_{y}^{a}}\right)-\cos \left(\frac{N_{m_{4}} y}{K_{y}^{a}}\right)\right] \\
& \times \frac{\cosh \left[\sqrt{\left(N_{m_{4}}\right)^{2}+\left(N_{n_{4}}\right)^{2}}\left(\frac{x}{K_{x}^{a}}\right)\right]-\cosh \left[\sqrt{\left(N_{m_{4}}\right)^{2}+\left(N_{n_{4}}\right)^{2}}\left(\frac{\varepsilon_{x}}{K_{x}^{a}}\right)\right]}{\sinh \left[\sqrt{\left(N_{m_{4}}\right)^{2}+\left(N_{n_{4}}\right)^{2}}\left(\frac{L}{K_{x}^{a}}\right)\right] \sqrt{\left(N_{m_{4}}\right)^{2}+\left(N_{n_{4}}\right)^{2}}} \\
& -\sum_{m_{5}=1}^{M_{5}} \sum_{n_{5}=1}^{N_{5}} F_{m_{5} n_{5}}\left(\frac{K_{x}^{a} K_{y}^{a}}{N_{m_{5}} N_{n_{5}}}\right) \tanh \left[\sqrt{\left(N_{m_{5}}\right)^{2}+\left(N_{n_{5}}\right)^{2}} h\right] \\
& \times \sqrt{\left(N_{m_{5}}\right)^{2}+\left(N_{n_{5}}\right)^{2}} \\
& \times\left[\cos \left(\frac{N_{m_{5}} \varepsilon_{x}}{K_{x}^{a}}\right)-\cos \left(\frac{N_{m_{5}} x}{K_{x}^{a}}\right)\right]\left[\cos \left(\frac{N_{n_{5}} \varepsilon_{y}}{K_{y}^{a}}\right)-\cos \left(\frac{N_{n_{5}} y}{K_{y}^{a}}\right)\right] \\
& +\sum_{p=1}^{P} \sum_{q=1}^{Q} \sum_{r=1}^{R} E_{p q r} N_{r}\left(\frac{K_{x}^{a} K_{y}^{a}}{N_{p} N_{q}}\right)\left[\cos \left(\frac{N_{p} \varepsilon_{x}}{K_{x}^{a}}\right)-\cos \left(\frac{N_{p} x}{K_{x}^{a}}\right)\right] \\
& \left.\times\left[\cos \left(\frac{N_{q} \varepsilon_{y}}{K_{y}^{a}}\right)-\cos \left(\frac{N_{q} y}{K_{y}^{a}}\right)\right] \exp \left[-\frac{\left(\lambda_{p q r}\right)^{2} t}{\left(K_{1}\right)^{2}}\right]\right\} \text {. }
\end{aligned}
$$

It is worth noting at this stage that $Q_{\text {top }}^{f}$ diverges when $x$ or $y$ or both fall exactly on an inner bund separating two unequal ponding depths at the surface of the soil. To prove this assertion, $Q_{\text {top }}^{f}$ may be determined exactly at an inner bund, say at $x=d_{x 1}$ separating the ponding depths $\delta_{1}$ and $\delta_{2}\left(\delta_{1} \neq \delta_{2}\right)$, and then the nature of this function be analysed for convergence for this setting. Towards realizing this end, $F_{m_{5} n_{5}}$ of Eq. (39) can be substituted in Eq. (27); this yields a term like 


$$
\begin{aligned}
& \left(\frac{4}{L_{X} B_{Y}}\right) \sum_{m_{5}=1}^{M_{5}} \sum_{n_{5}=1}^{N_{5}} \delta_{1}\left[\frac{K_{x}^{a} K_{y}^{a}}{N_{m_{5}}\left(N_{n_{5}}\right)^{2}}\right] \times \cos ^{2}\left(N_{m_{5}} S_{X 1}\right) \\
& \times \cos \left(N_{n_{5}} Y\right) \times \cos \left(N_{n_{5}} S_{Y\left(2 N_{0}-2\right)}\right) \times \sqrt{1+\left(\frac{N_{n_{5}}}{N_{m_{5}}}\right)^{2}} \\
& \quad \times \tanh \left[\sqrt{\left(N_{m_{5}}\right)^{2}+\left(N_{n_{5}}\right)^{2}} h\right] .
\end{aligned}
$$

Now, for a particular value of $n_{5}$, it is easy to see that both $\tanh \left[\sqrt{\left(N_{m_{5}}\right)^{2}+\left(N_{n_{5}}\right)^{2}} h\right]$ and $\sqrt{1+\left(\frac{N_{n_{5}}}{N_{m_{5}}}\right)^{2}}$ tend to 1 when $m_{5}$ is made to increase without any upper margin, that is

$$
\operatorname{Lim}_{m_{5} \rightarrow \infty}\left\{\tanh \left[\sqrt{\left(m_{5} \pi / L_{X}\right)^{2}+\left(N_{n_{5}}\right)^{2}} h\right]\right\}=1
$$

and

$$
\operatorname{Lim}_{m_{5} \rightarrow \infty}\left\{\sqrt{1+\left(\frac{L_{X} N_{n_{5}}}{m_{5} \pi}\right)^{2}}\right\}=1 .
$$

If it is supposed that $\tanh \left[\sqrt{\left(N_{m_{5}}\right)^{2}+\left(N_{n_{5}}\right)^{2}} h\right]$ and $\sqrt{1+\left(\frac{N_{m_{5}}}{N_{n_{5}}}\right)^{2}}$ reach approximately 1 after summing up to approximately four terms of $m_{5}$ for a given value of $n_{5}$, then the above infinite series can be expressed as $\left(\frac{4}{L_{X} B_{Y}}\right) \sum_{m_{5}=5}^{M_{5}} \delta_{1}$ $\left[\frac{K_{x}^{a} K_{y}^{a}}{N_{m_{5}}\left(N_{n_{5}}\right)^{2}}\right] \cos ^{2}\left(N_{m_{5}} S_{X 1}\right) \cos \left(N_{n_{5}} Y\right) \cos \left(N_{n_{5}} S_{Y\left(2 N_{0}-2\right)}\right)$.If now $N_{m_{5}}$ of Eq. (17) is plugged into this series, then it reduces, after some simplification, to the form

$$
\begin{aligned}
\omega(\text { say })= & \left(\frac{4 \delta_{1}}{\pi B_{Y}}\right) \sum_{m_{5}=5}^{M_{5} \rightarrow \infty}\left[\frac{K_{x}^{a} K_{y}^{a}}{m_{5}\left(N_{n_{5}}\right)^{2}}\right] \\
& \times \cos ^{2}\left(m_{5} \pi \alpha\right) \cos \left(N_{n_{5}} Y\right) \cos \left(N_{n_{5}} S_{Y\left(2 N_{0}-2\right)}\right),
\end{aligned}
$$

where $\alpha=S_{X 1} / L_{X}(0<\alpha<1)$. As $\cos ^{2}\left(m_{5} \pi \alpha\right)$ lies between 0 and 1 for all possible values of $m_{5}$ [i.e., $0 \leq \cos ^{2}\left(m_{5} \pi \alpha\right) \leq 1, m_{5} \in\{1,2,3, \ldots\} ;$ in the expression for $\omega, m_{5}$ starts from 5], there can be two possibilities for a particular value of $\alpha$, namely, $\cos ^{2}\left(m_{5} \pi \alpha\right) \neq 0$ for any value of $m_{5} \in\{5,6,7, \ldots\}$ or $\cos ^{2}\left(m_{5} \pi \alpha\right)=0$ for a subset of positive integers, say, $\left\{m_{n 1}, m_{n 2}, m_{n 3}, \ldots\right\}$ belonging to the set $m_{5} \in\{5,6,7, \ldots\}$ (i.e., $\left.m_{n i} \in\{5,6,7, \ldots\}\right)$. Considering the first case first and letting $M_{\min }=$ minimum of $\cos ^{2}\left(m_{5} \pi \alpha\right)$ for any $m_{5} \in\{5,6,7, \ldots\}$, the following inequality then can be written:

$$
\begin{gathered}
M_{\min }\left(\frac{4 \delta_{1}}{\pi B_{Y}}\right)\left[\frac{K_{x}^{a} K_{y}^{a}}{\left(N_{n_{5}}\right)^{2}}\right] \cos \left(N_{n_{5}} Y\right) \cos \left(N_{n_{5}} S_{Y\left(2 N_{0}-2\right)}\right) \sum_{\substack{m_{5}=5 \\
M_{5} \rightarrow \infty}}^{M_{m_{5}}}<\left(\frac{4 \delta_{1}}{\pi B_{Y}}\right)\left[\frac{K_{x}^{a} K_{y}^{a}}{\left(N_{n_{5}}\right)^{2}}\right] \cos \left(N_{n_{5}} Y\right) \cos \left(N_{n_{5}} S_{Y\left(2 N_{0}-2\right)}\right) \sum_{m_{5}=5}^{M_{5} \rightarrow \infty}
\end{gathered}
$$

$\left[\frac{\cos ^{2}\left(m_{5} \pi \alpha\right)}{m_{5}}\right]$. However, $\sum_{m_{5}=5}^{M_{5} \rightarrow \infty}\left(\frac{1}{m_{5}}\right)$ diverges and hence the left hand and the right side of the inequality too. In other words, $\omega$ diverges when $\cos ^{2}\left(m_{5} \pi \alpha\right) \neq 0$.

Now, to prove the divergence of $\omega$ when $\cos ^{2}\left(m_{5} \pi \alpha\right)=0$ for any $m_{5} \in\left\{m_{n 1}, m_{n 2}, m_{n 3}, \ldots\right\}$ the infinite series of $\omega$ can be split into two parts as follows:

$$
\begin{aligned}
\omega(\text { say })= & \left(\frac{4 \pi \delta_{1}}{B_{Y}}\right)\left[\frac{K_{x}^{a} K_{y}^{a}}{\left(N_{n_{5}}\right)^{2}}\right] \cos \left(N_{n_{5}} Y\right) \\
& \times \cos \left(N_{n_{5}} S_{Y\left(2 N_{0}-2\right)}\right) \sum_{m_{n i}}^{M_{5} \rightarrow \infty}\left[\frac{\cos ^{2}\left(m_{5} \pi \alpha\right)}{m_{5}}\right] \\
& +\left(\frac{4 \pi \delta_{1}}{B_{Y}}\right)\left[\frac{K_{x}^{a} K_{y}^{a}}{\left(N_{n_{5}}\right)^{2}}\right] \cos \left(N_{n_{5}} Y\right) \cos \left(N_{n_{5}} S_{Y\left(2 N_{0}-2\right)}\right) \\
& \sum_{m_{5}}^{M_{5} \rightarrow \infty}\left[\frac{\cos ^{2}\left(m_{5} \pi \alpha\right)}{m_{5}}\right] .
\end{aligned}
$$

Naturally, the first term of the above series is zero as $\cos ^{2}\left(m_{5} \pi \alpha\right)=0$ for all $m_{5}$ belonging to the subset $\left\{m_{n 1}, m_{n 2}, m_{n 3}, \ldots\right\}$. Also, the following inequality is valid for $\quad$ all $m_{5} \in\{5,6,7, \ldots\} \backslash\left\{m_{n 1}, m_{n 2}, m_{n 3}, \ldots\right\}=\left\{m_{p 1}\right.$, $\left.m_{p 2}, m_{p 3}, \ldots\right\}$ (say):

$$
\begin{aligned}
M_{\min }^{\prime} & \left(\frac{4 \delta_{1}}{\pi B_{Y}}\right)\left[\frac{K_{x}^{a} K_{y}^{a}}{\left(N_{n_{5}}\right)^{2}}\right] \cos \left(N_{n_{5}} Y\right) \cos \left(N_{n_{5}} S_{Y\left(2 N_{0}-2\right)}\right) \sum_{m_{5}}^{M_{5} \rightarrow \infty}\left(\frac{1}{m_{5}}\right) \\
< & \left(\frac{4 \delta_{1}}{\pi B_{Y}}\right)\left[\frac{K_{x}^{a} K_{y}^{a}}{\left(N_{n_{5}}\right)^{2}}\right] \cos \left(N_{n_{5}} Y\right) \cos \left(N_{n_{5}} S_{Y\left(2 N_{0}-2\right)}\right) \\
& \sum_{m_{5}}^{M_{5} \rightarrow \infty}\left[\frac{\cos ^{2}\left(m_{5} \pi \alpha\right)}{m_{5}}\right],
\end{aligned}
$$

where $M_{\min }^{\prime}=$ minimum of $\cos ^{2}\left(m_{5} \pi \alpha\right)$ for $m_{5} \in\left\{m_{p 1}, m_{p 2}, m_{p 3}, \ldots\right\}$. But here also

$$
M_{\text {min }}^{\prime}\left(\frac{4 \delta_{1}}{\pi B_{Y}}\right)\left[\frac{K_{x}^{a} K_{y}^{a}}{\left(N_{n_{5}}\right)^{2}}\right] \cos \left(N_{n_{5}} Y\right) \cos \left(N_{n_{5}} S_{Y 6}\right)\left(\frac{1}{m_{p 1}}+\frac{1}{m_{p 2}}+\frac{1}{m_{p 2}}\right.
$$

$+\ldots)$ diverges; thus $\omega$, and hence $Q_{\text {top }}^{f}\left(x=d_{x 1}, y, t\right)$, diverges for both the scenarios when $\cos ^{2}\left(m_{5} \pi \alpha\right) \neq 0$ and $\cos ^{2}\left(m_{5} \pi \alpha\right)=0$. A similar procedure can be adopted to show the divergence of $Q_{\text {top }}^{f}$ when it is being measured exactly at any other inner bunds.

Thus, the total discharge, $Q_{\text {top }}$, infiltrating through the surface of the soil at any instant of time $t$ for situations where $\delta_{1} \neq 0$ can next be easily worked out by simply substituting $x=L-\varepsilon_{x}$ and $y=B-\varepsilon_{y}$ in Eq. (27), that is

$$
Q_{\mathrm{top}}=Q_{\mathrm{top}}^{f}\left(x=L-\varepsilon_{x}, y=B-\varepsilon_{y}, t\right) .
$$

Thus, it can be seen that, at a point of piecewise discontinuity, be it at the edges of the field or exactly at an inner bund separating two dissimilar water level heights, the discharge function (as well as the velocity functions) 
blows up. However, a point of jump discontinuity can be avoided by considering a deleted neighbourhood (naturally, smaller the size of this neighbourhood, greater the accuracy) and that is why $\varepsilon_{x}$ and $\varepsilon_{y}$ are to be chosen with finite values should there exist jump discontinuity points at the edges of the field (say, when $\delta_{1}$ is non-zero). The same is also true when an inner bund separates two different water level heights (i.e., say when $\delta_{i-1} \neq \delta_{i}$ ). However, since the top boundary condition utilized for deriving the hydraulic head function assumes a known ponding distribution throughout the surface of the soil (i.e., treats the surface boundary as a purely Dirichlet boundary as in Kirkham $[19,20])$, naturally, the application of this solution for finite-sized side and inner bunds will lead to error. This error, however, can be made virtually non-existent if the widths of the bunds are treated as infinitesimals. This is also true for most of the leaching scenarios where the widths of side bunds are generally much lower than that of the spacing between the ditches (Kirkham [19, 20], Warrick and Kirkham [27]). It is important to note here that if the soil is being subjected to a negligible ponding head at the surface of the soil (i.e., $\delta_{j}=0$ ), no bund will then be required at the surface of the field and the proposed solution will then be strictly accurate. It is worth remarking here that, even for the case of zero ponding (i.e., by assuming zero depth of ponding over the surface of the soil) and steady-state flow, there currently exists no analytical solution to the three-dimensional ditch drainage problem. Thus, when $\delta_{1}=0$, the lower limits of integration of the integral of Eq. (27) can then be treated as zero (i.e., $\varepsilon_{x}=\varepsilon_{y}=0$ ) but when $\delta_{1} \neq 0$, side bunds are then a necessity (as otherwise, water from the surface will just directly flow to the drains) and hence some finite values of the side bunds $\left(\varepsilon_{x} \neq 0, \varepsilon_{y} \neq 0\right)$ need to be put in the integral, as otherwise the integral will diverge (as shown earlier). As $\varepsilon_{x}$ and $\varepsilon_{y}$ can be given a much smaller value as compared with the spacing between the ditches (Kirkham [19, 20], Warrick and Kirkham [27]) for a typical leaching scenario, the error resulting due to consideration of finite values of $\varepsilon_{x}$ and $\varepsilon_{y}$ is expected to be quite limited for such a situation. Now, as far as the upper limits of Eq. (27) are concerned, as long as both the limits do not fall exactly on points of jump discontinuity separating different water level heights (i.e., exactly on locations separating, say, $\delta_{i-1} \neq \delta_{i}$ ), the integral will converge as has been proved before. However, in the case where even one of the upper limits falls exactly on a point of piece discontinuity, say at $x=d_{x 1}$ separating the ponding depths $\delta_{1}$ and $\delta_{2}\left(\delta_{1} \neq \delta_{2}\right)$, the integral will then, as shown before, diverge. For such a situation, the upper limit of $x$ may be taken as $d_{x 1} \pm \varepsilon$, where $\varepsilon \rightarrow 0$ (but not exactly zero; that is by considering a point in the deleted neighbourhood of $d_{x 1}$ ). If the upper limits fall on any other point other than the piecewise continuous points, the integral will converge.
For better clarity of presentation, the top discharge function can also be normalized in percentage form by dividing $Q_{\text {top }}^{f}$ by $Q_{\text {top }}$ and then multiplying the resultant by 100 ; denoting such a function as $Q_{\text {top }}^{n f}$, an expression for the same can thus be represented as

$$
Q_{\text {top }}^{n f}=\left(\frac{Q_{\text {top }}^{f}}{Q_{\text {top }}}\right) \times 100 .
$$

It will now be shown that $Q_{\text {top }}$ diverges if $\delta_{1}$, the ponding depth in the first annular strip (figure 1), is non-zero but $\varepsilon_{x}$ and/or $\varepsilon_{y}$ is zero at the same time. For that, we substitute $F_{m_{5} n_{5}}$ of Eq. (39) in Eq. (28); this results in an expression having a term, for $\varepsilon_{x}=0$, like

$$
\begin{aligned}
& \left(\frac{2}{B_{Y}}\right)\left(\frac{2}{L_{X}}\right) \sum_{m_{5}=1}^{M_{5}} \sum_{n_{5}=1}^{N_{5}} \delta_{1}\left[\frac{K_{x}^{a} K_{y}^{a}}{N_{n_{5}}\left(N_{m_{5}}\right)^{2}}\right] \\
& \tanh \left[\sqrt{\left(N_{m_{5}}\right)^{2}+\left(N_{n_{5}}\right)^{2}} h\right] \sqrt{1+\left(\frac{N_{m_{5}}}{N_{n_{5}}}\right)^{2}}
\end{aligned}
$$

where $N_{m_{5}}=m_{5} \pi / L_{X}$ and $N_{n_{5}}=n_{5} \pi / B_{Y}$. Now, for a particular value of $m_{5}$, it can be seen that $\tanh \left[\sqrt{\left(N_{m_{5}}\right)^{2}+\left(N_{n_{5}}\right)^{2}} h\right]$ and $\sqrt{1+\left(\frac{N_{m_{5}}}{N_{n_{5}}}\right)^{2}}$ of the above series tend to 1 when $n_{5}$ is allowed to increase continually, that is

$$
\operatorname{Lim}_{\mathrm{n}_{5} \rightarrow \infty}\left\{\tanh \left[\sqrt{\left(N_{m_{5}}\right)^{2}+\left(n_{5} \pi / B_{Y}\right)^{2}} h\right]\right\}=1
$$

and

$$
\operatorname{Lim}_{n_{5} \rightarrow \infty}\left\{\sqrt{1+\left(\frac{B_{Y} N_{m_{5}}}{n_{5} \pi}\right)^{2}}\right\}=1 .
$$

If it is assumed that $\tanh \left[\sqrt{\left(N_{m_{5}}\right)^{2}+\left(N_{n_{5}}\right)^{2}} h\right]$ and $\sqrt{1+\left(\frac{N_{m_{5}}}{N_{n_{5}}}\right)^{2}}$ reach approximately 1 after summing up to four terms of the inside summation of the double summation series of above for a particular $m_{5}$, then

$$
\begin{aligned}
& \left(\frac{2}{B_{Y}}\right)\left(\frac{2}{L_{X}}\right) \sum_{m_{5}=1}^{M_{5} \rightarrow \infty} \sum_{n_{5}=1}^{N_{5} \rightarrow \infty} \delta_{1}\left[\frac{B_{Y} K_{x}^{a} K_{y}^{a}}{n_{5} \pi\left(N_{m_{5}}\right)^{2}}\right] \\
& \times \tanh \left[\sqrt{\left(N_{m_{5}}\right)^{2}+\left(n_{5} \pi / B_{Y}\right)^{2}} h\right] \sqrt{1+\left(\frac{B_{Y} N_{m_{5}}}{n_{5} \pi}\right)^{2}}
\end{aligned}
$$

reduces to a series of the nature

$$
\left(\frac{4 \delta_{1}}{\pi L_{X}}\right)\left[\frac{K_{x}^{a} K_{y}^{a}}{\left(N_{m_{5}}\right)^{2}}\right]\left(\frac{1}{5}+\frac{1}{6}+\frac{1}{7}+\ldots\right),
$$


an infinite series, which, as is known, diverges. Since this is true for any chosen value of $m_{5}$, it can thus be concluded that

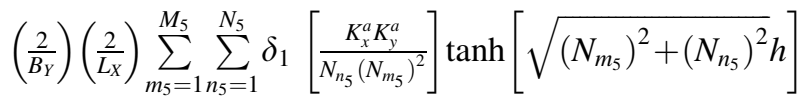
$\sqrt{1+\left(\frac{N_{m_{5}}}{N_{n_{5}}}\right)^{2}}$, and hence $Q_{\mathrm{top}}$, always diverges if $\delta_{1}$ is not zero but $\varepsilon_{x}$ is zero at the same time. In a similar way, it can also be shown that $\delta_{1} \neq 0$ and $\varepsilon_{y}=0$ at the same time, also, makes $Q_{\text {top }}$ diverge.

It is worth noting at this point that the volume of water seeping through the surface of the soil or being fed to a drainage ditch during a specific time $T$ can also be easily determined, by carrying out a time integral on the discharge function of interest for the duration $T$. Thus, the volume of water seeping through the surface of the soil in time $T$ can be calculated as

$$
V o l_{\text {top }}=\int_{0}^{T} Q_{\text {top }}(t) d t
$$

In the same way, the volume of water seeping into the North, South, East and West ditches in time $T$ can also be determined by carrying out time integrals of the relevant discharges for the concerned duration.

The path traversed by a water particle from the surface of the soil to a ditch can be traced by following an iterative procedure as given by Grove et al [43]. This procedure also gives the time of travel of a fluid particle between any two locations in the pathline of the particle. This methodology can be used to trace not only a streamline but also a streamsurface as well, a streamsurface being the locus of infinite number of streamlines being originated from a continuous line segment (Hultquist [44, 45]. It is to be noted that the pathlines and the streamsurfaces shown in figure 4-8, 11 and 12 have been traced using the method as just mentioned.

\section{Verification of the proposed solution}

A few checks are now performed to establish the validity of the analytical solution proposed here. In the first instance, a comparison is being made between the hydraulic heads as obtained from this solution and the corresponding values obtained from an earlier analytical solution of the fully penetrating ponded ditch drainage problem developed utilizing the two-dimensional flow assumption. It is to be noted that the three-dimensional ponded drainage problem considered here should approximately reduce to that of a two-dimensional one in a vertical plane located further away from the Northern and Southern boundaries of figure 1 , if $B$ is given a very large value. Thinking on this line, a comparison study was carried out between the hydraulic head predictions as obtained from the proposed solutions and the corresponding values obtained from Barua and Alam's solution for a specific drainage situation of figure 1 in a vertical plane passing midway (i.e., the vertical plane located at $y=25 \mathrm{mfrom}$ the origin where the flow was expected to be approximately two-dimensional in nature for the considered drainage situation) between the Northern and Southern boundaries of the flow domain. Figure 2 shows the comparison of this model. As can be seen, the hydraulic heads as obtained from the developed model match closely with the corresponding values as obtained from Barua and Alam's solution for the chosen flow situation, thereby showing that the proposed solution is correctly developed. Also, for this drainage situation, $\frac{Q_{\text {top }}(x=0 \text { to } L, y=25 \text { to } 26, t \rightarrow \infty)}{2 K h}$ ratios work out to be 0.741 , where the discharges in the above ratios have been taken between the vertical planes passing through $y=25 \mathrm{~m}$ and $y=26 \mathrm{~m}$.On the other hand, this ratio, when evaluated utilizing using Fukuda's [22] and Youngs' [3] analytical solutions, turns out as 0.743 and 0.742 , respectively values that are very close to the value of 0.741 obtained from the model proposed here and thereby providing with another check on the validity of the proposed solution. Further, Fukuda also found this ratio as 0.720 from his experimental observations. Thus, the close matching of this ratio as obtained from the proposed model with the identical ratio obtained from Fukuda's experimental results can also be treated as an experimental verification of the solution being proposed here.

In order to ascertain once again the correctness of the developed analytical model, a numerical check on the developed model was also performed by drawing an appropriate numerical model utilizing the Processing MODFLOW [46] codes. Figure 3 shows comparison of numerically obtained hydraulic heads corresponding to a time step for a chosen ponded drainage situation of figure 1 to the corresponding analytical values; as may be seen, the analytically predicted hydraulic heads are in close conformity with the numerically obtained values, thereby showing once again that the proposed solution has been correctly developed.

\section{Discussion}

From figures 4-8 it is clear that flow to a ditch drainage system from a ponded field of finite and limited size is mostly of a three-dimensional nature, particularly in areas close to the drains. It can also be observed from figure 8 that, even for drainage situations where two parallel vertical faces of the flow domain are separated from each other by a relatively large distance as compared with the separation distance between the other two faces, three-dimensional nature of the pathlines still prevails, mainly again in locations close to the drains. However, from this figure (i.e., 


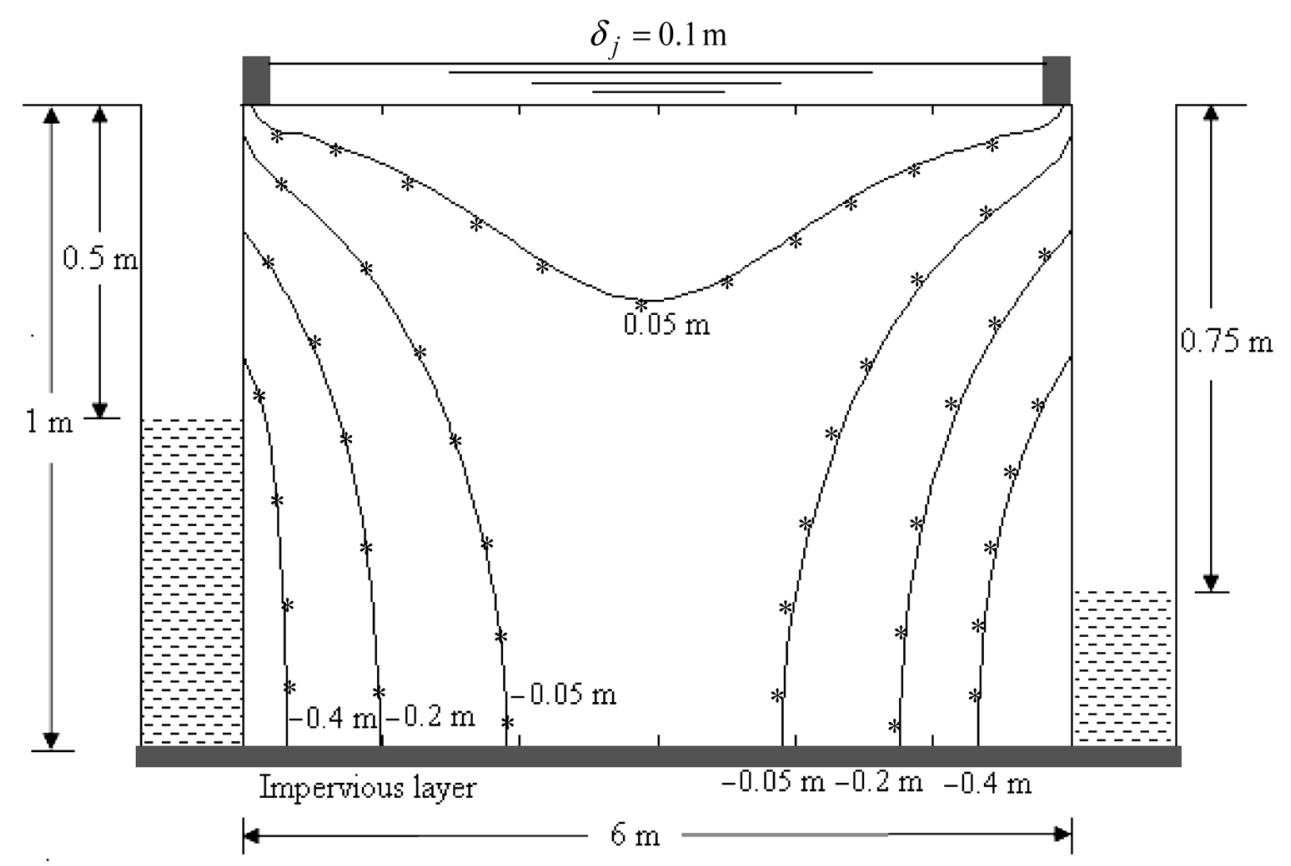

Figure 2. Comparison of hydraulic head contours as obtained from the proposed analytical solution with the corresponding values as obtained from the analytical solution of Barua and Alam [10] at time $t=15 \mathrm{~s}$ and at $y=25 \mathrm{~m}$ (i.e., at the mid-plane between the Northern and Southern boundaries) when the flow parameters are taken as $L=6 \mathrm{~m}, B=50 \mathrm{~m}, h=1 \mathrm{~m}, S_{s}=0.001 \mathrm{~m}^{-1}, H_{1}=0.5 \mathrm{~m}$, $H_{2}=0.5 \mathrm{~m}, H_{3}=0.75 \mathrm{~m}, H_{4}=0.5 \mathrm{~m}, K_{x}=5 \mathrm{~m} /$ day, $K_{y}=1 \mathrm{~m} /$ day, $K_{z}=1 \mathrm{~m} /$ day, $\delta_{j}=0.1 \mathrm{~m}, \varepsilon_{x}=0.1 \mathrm{~m}$ and $\varepsilon_{y}=0.1 \mathrm{~m}$. Transient hydraulic head contour as generated by the proposed analytical solution of Eq. (2)* Transient hydraulic head contour as generated by the analytical solution of Barua and Alam [10].

figure 8) it is also evident that, in a vertical plane located further away from the longer side boundaries, flow can roughly be approximated as a two-dimensional one without introducing any appreciable error when measured vis-à-vis a three-dimensional model. It may also be noticed that the flow situation as shown in figure 1 can also very well represent subsurface flow to a straight river reach from a flooded field of negligible depth of flood water over the surface of the soil. In fact, Brainard and Gelhar [17] also performed similar studies using the finite-element method for predicting three-dimensional seepage of water into a straight river reach of finite length from a horizontal field receiving a uniform recharge at the water table. Their numerical studies, however, as just mentioned, assume a uniform recharge input at the water table whereas the analytical models proposed here assume a known ponding distribution at the surface of the soil. It is also clear from figure $4 \mathrm{a}$ and $\mathrm{b}$ that an increase in the vertical conductivity causes not only the pathlines to penetrate relatively deeper into a drainage space but also brings about a considerable reduction in the water particle travel times along the pathlines as well. The travel times are also, expectedly, found to decrease with the increase of the ponding head at the surface of the soil, as can be clearly seen in figures $4 \mathrm{~b}$ and 6 . Also, from figures $4 \mathrm{~b}$ and 5 , it can be seen that by merely changing the level of water in the ditches, extensive changes in the pathline distribution as well as on the travel times of water particles can be brought about; whereas the pathline originating from the coordinate $(2,4,0)$ exits through the Northern boundary for the flow situation of figure $4 \mathrm{~b}$, a mere change of ditch water levels in the North, South, East and West drains for this flow scenario from 0.5 to $0.25,0.5,0.75$ and $0.75 \mathrm{~m}$, respectively, has now caused the $(2,4,0)$ pathline to exit through the Western boundary (figure 5).

Further, the travel times for these drainage situations are also significantly different from each other. Another important variable, so far as the travel times of water particles in a ponded drainage is concerned, is the thickness of the soil column overlying the impervious barrier. Other factors remaining the same, an increase in this thickness may result in a substantial increase of the water particle travel times along the pathlines, as has been aptly demonstrated through the drainage situations of figures $4 \mathrm{~b}$ and 7 .

Figure 9 shows the variations of $Q_{\text {top }} / 2 K h[K=$ $\left.\left(K_{x} K_{y} K_{z}\right)^{1 / 3}\right]$ with time for a few flow situations of figure 1 . From these figures, it is apparent that the time taken by a three-dimensional ponded ditch drainage system to attain steady state may be considerable if the directional conductivities of the soil are low and the specific storage is high. This is all the more true for situations where the 


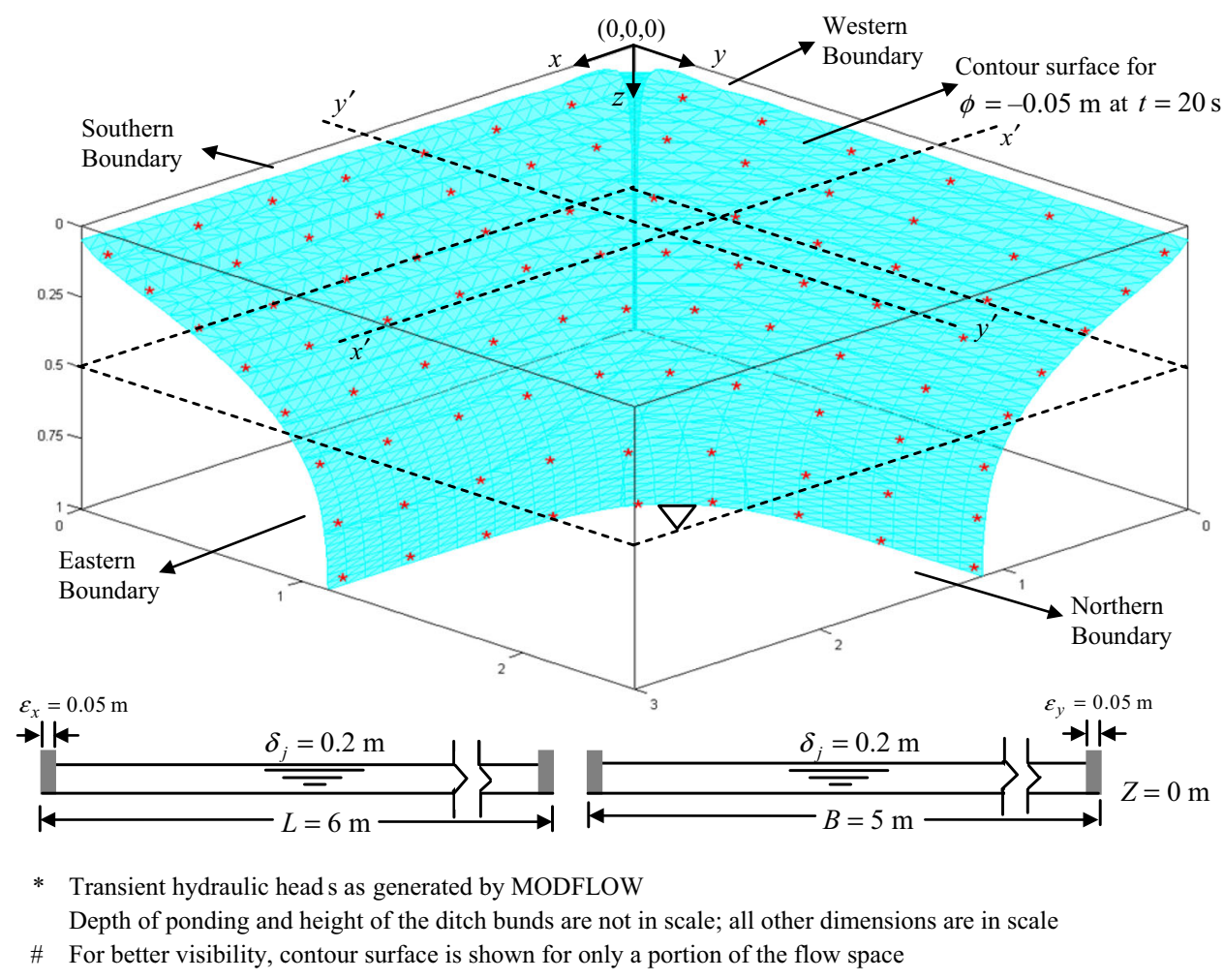

Figure 3. Comparison of hydraulic head contour surface as obtained from the proposed analytical solution with the corresponding MODFLOW generated contours at time $t=20 \mathrm{~s}$ when the flow parameters are taken as $L=6 \mathrm{~m}, B=5 \mathrm{~m}, h=1 \mathrm{~m}, S_{s}=0.001 \mathrm{~m}^{-1}$, $H_{1}=0.5 \mathrm{~m}, H_{2}=0.5 \mathrm{~m}, H_{3}=0.5 \mathrm{~m}, H_{4}=0.5 \mathrm{~m}, K_{x}=1 \mathrm{~m} /$ day, $K_{y}=1 \mathrm{~m} /$ day, $K_{z}=0.2 \mathrm{~m} /$ day, $\delta_{j}=0.2 \mathrm{~m}, \varepsilon_{x}=0.05 \mathrm{~m}$ and $\varepsilon_{y}=$ $0.05 \mathrm{~m}$. * Transient hydraulic heads as generated by MODFLOW. Depth of ponding and height of the ditch bunds are not in scale; all other dimensions are in scale. \# For better visibility, contour surface is shown for only a portion of the flow space.

ditches are dug relatively deeper into the ground. These graphs also show that, considering all the other factors to remain the same, a decrease in vertical hydraulic conductivity of a soil column may result in a considerable increase in the transient state duration of a three-dimensional ponded drainage system, particularly in areas where the thickness of the soil is large and the drains are dug all the way through it. As the hydraulic conductivities of most of the natural deposits along the bedding planes are generally higher than that across it $[47,48]$ and lowly conductive soils like glacial tills, dense clays and clayey paddy soils are also quite common in nature [49-52] and further since the specific storage of soils like glacial tills and lacustrine clays can also be quite high [53-57], the transient state duration of a three-dimensional ditch drainage system may be quite high for many drainage situations.

Figure 10 shows the variation of the normalized top discharge function for a drainage situation of figure 1 for two different times. It is interesting to note from this figure that the discharge distribution at the surface of a ponded soil in a three-dimensional ditch drainage system at a very early time of simulation is relatively much more uniform than that corresponding to a later time. This uniformity, however, breaks down at large times and as may be observed in figure 10, the percentage of water seeping from different surficial locations of a uniformly ponded drainage scenario may be a pretty uneven one at a large time of simulation of the system, with most water seeping into the drains being contributed from locations lying close to the drains. However, by subjecting a suitable ponding distribution over the surface of the soil specific to a drainage situation, a much better uniformity of seepage at the surface of the soil can be brought about. This is amply demonstrated in figure 12 where, as may be observed, the imposition of a variable ponding field of the type as shown has resulted in a relatively much more uniform distribution of discharge at the surface of the soil as compared with the situation when the ponded surface is being subjected to only a uniform ponding depth. Figures 11 and 12 further show that the introduction of the variable ponding also causes the uniformity of the travel times of water particles moving along different streamlines to improve considerably. This uniformity is more pronounced when travel times of the particles are traced to a relatively short vertical distance from the surface of the soil. Thus, to reclaim a saltaffected soil within a specified time, the proposed solution 
(a)

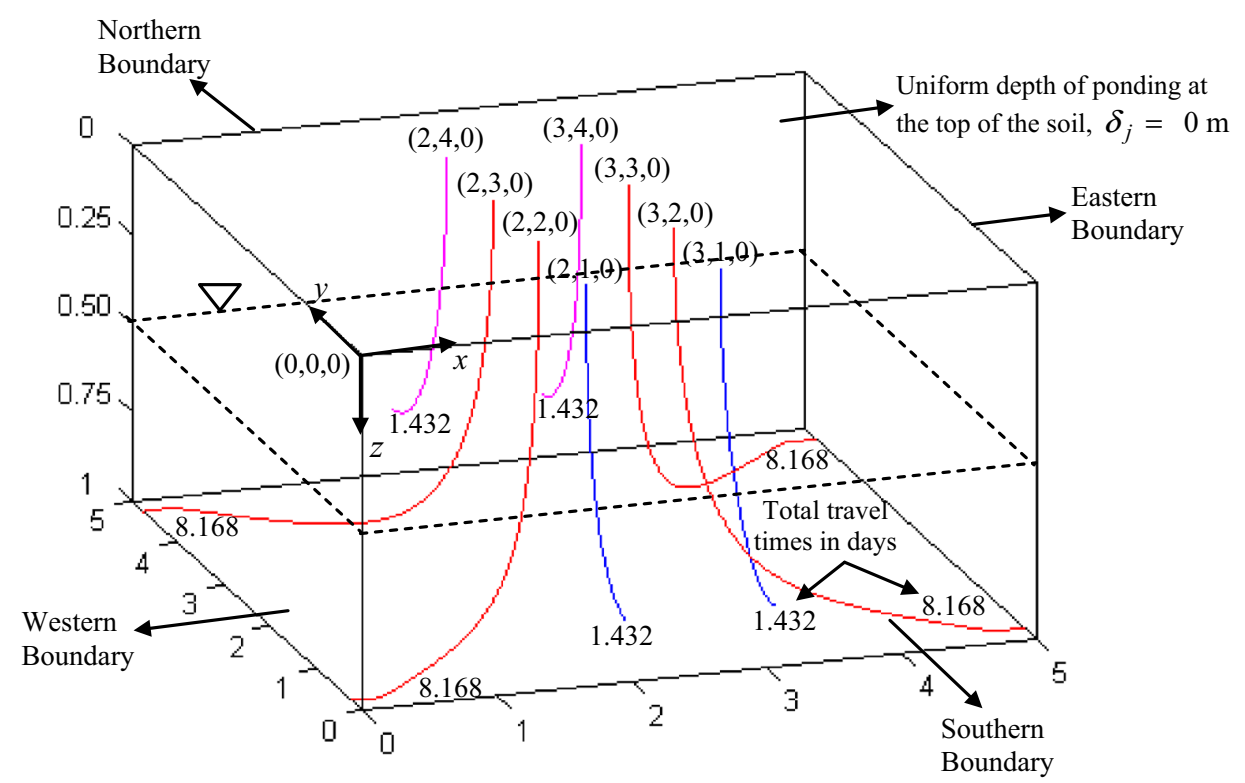

(b)

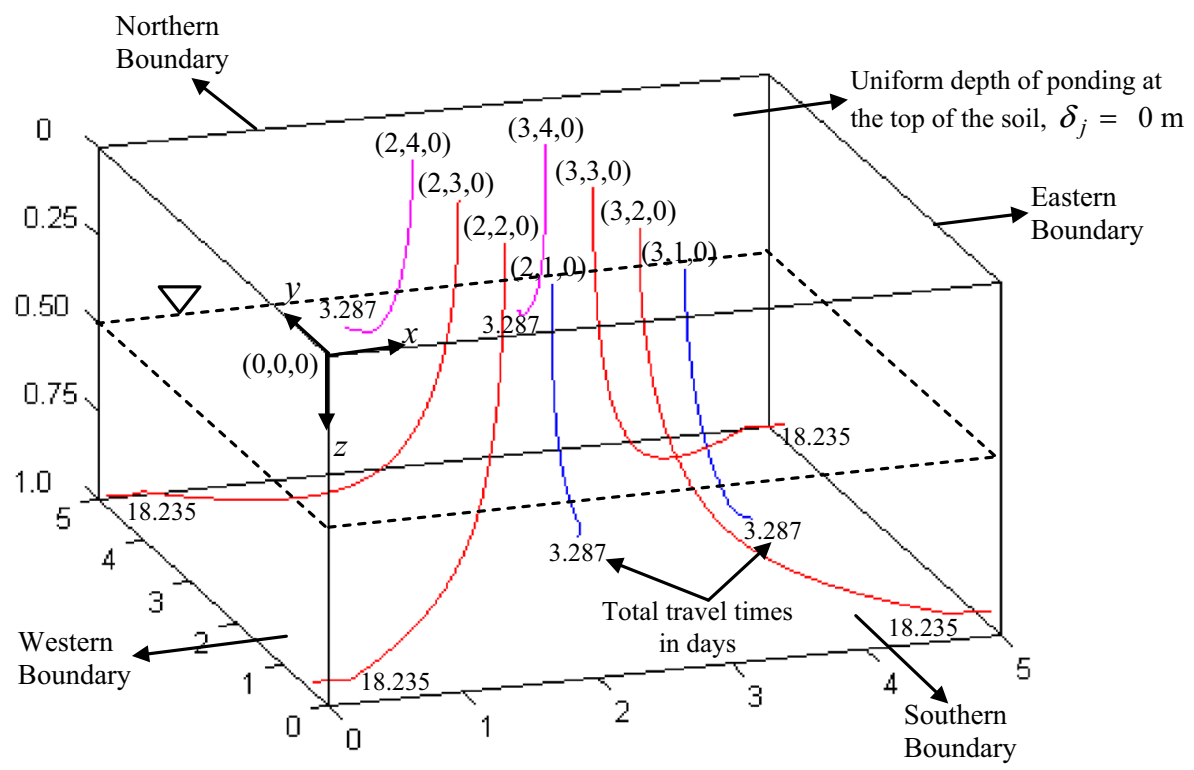

Figure 4. Travel times of water particles (in days) on a few pathlines starting from the surface of the soil to the recipient ditches under steady state condition when the parameters of figure 1 are taken as $L=5 \mathrm{~m}, B=5 \mathrm{~m}, h=1 \mathrm{~m}, H_{1}=0.5 \mathrm{~m}, H_{2}=0.5 \mathrm{~m}, H_{3}=0.5 \mathrm{~m}$, $H_{4}=0.5 \mathrm{~m}, \delta_{j}=0 \mathrm{~m}, \eta=0.3$, (a) $K_{x}=K_{y}=K_{z}=1 \mathrm{~m} /$ day (b) $K_{x}=K_{y}=1 \mathrm{~m} /$ day and $K_{z}=0.1 \mathrm{~m} /$ day.

can be suitably utilized to work out appropriate ponding distribution and depth and spacing of ditch drains so that adequate quantities of water seep through different locations of the drained soil column within the desired time. It is also worth noting here that purely vertical earthen ditch drains of large depth may exhibit instability, particularly when installed in loosely bonded soils. However, this should not be a major impediment to the application of the proposed solution as it has been mainly developed for designing drainage ditches for reclaiming root zones of saltaffected cropped fields, which for most of the crops are mostly restricted within a few metres from the top of the soil (Lundstrom and Stegman [58]; Hoorn and Alphen [1]; Ayars et al $[59,60]$ - to cite a few). The solution provided 


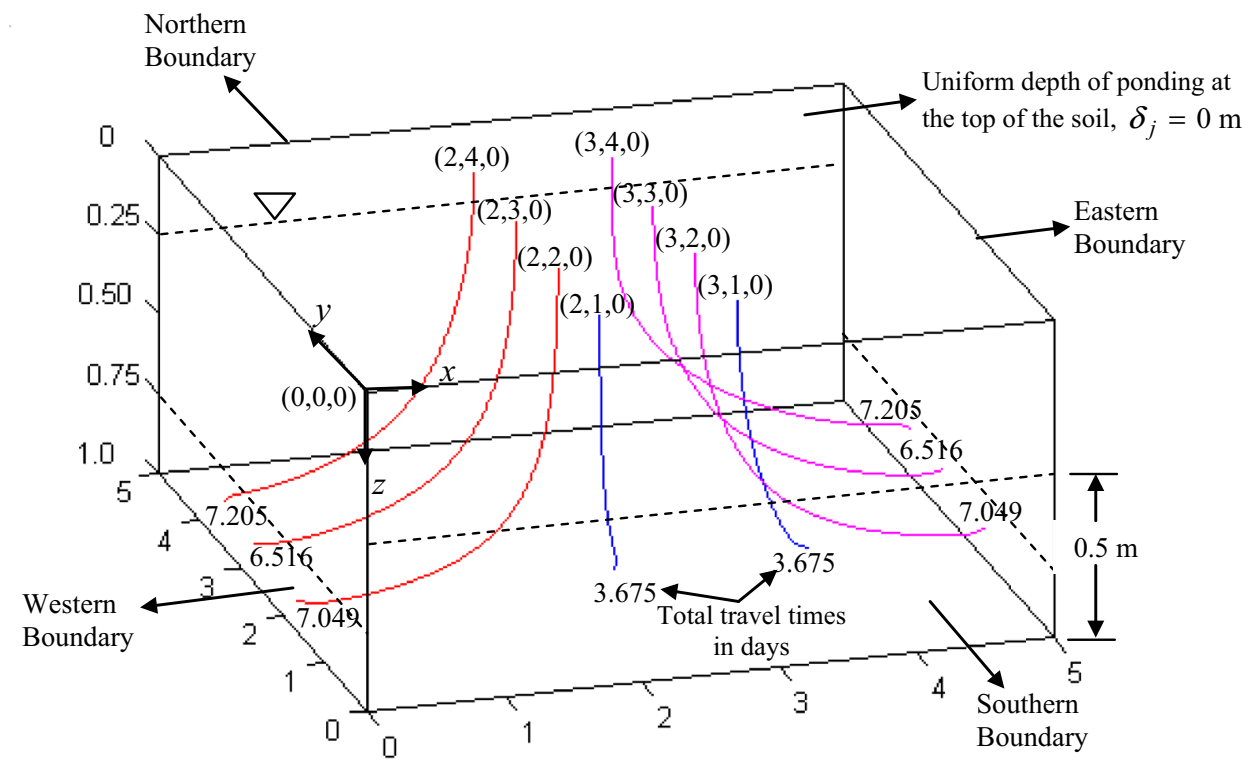

Figure 5. Travel times of water particles (in days) on a few pathlines starting from the surface of the soil to the recipient ditches under steady state condition when the parameters of figure 1 are taken as $L=5 \mathrm{~m}, B=5 \mathrm{~m}, h=1 \mathrm{~m}, H_{1}=0.25 \mathrm{~m}, H_{2}=0.5 \mathrm{~m}, H_{3}=$ $0.75 \mathrm{~m}, H_{4}=0.75 \mathrm{~m}, \delta_{j}=0 \mathrm{~m}, \eta=0.3, K_{x}=K_{y}=1 \mathrm{~m} /$ day and $K_{z}=0.1 \mathrm{~m} /$ day.

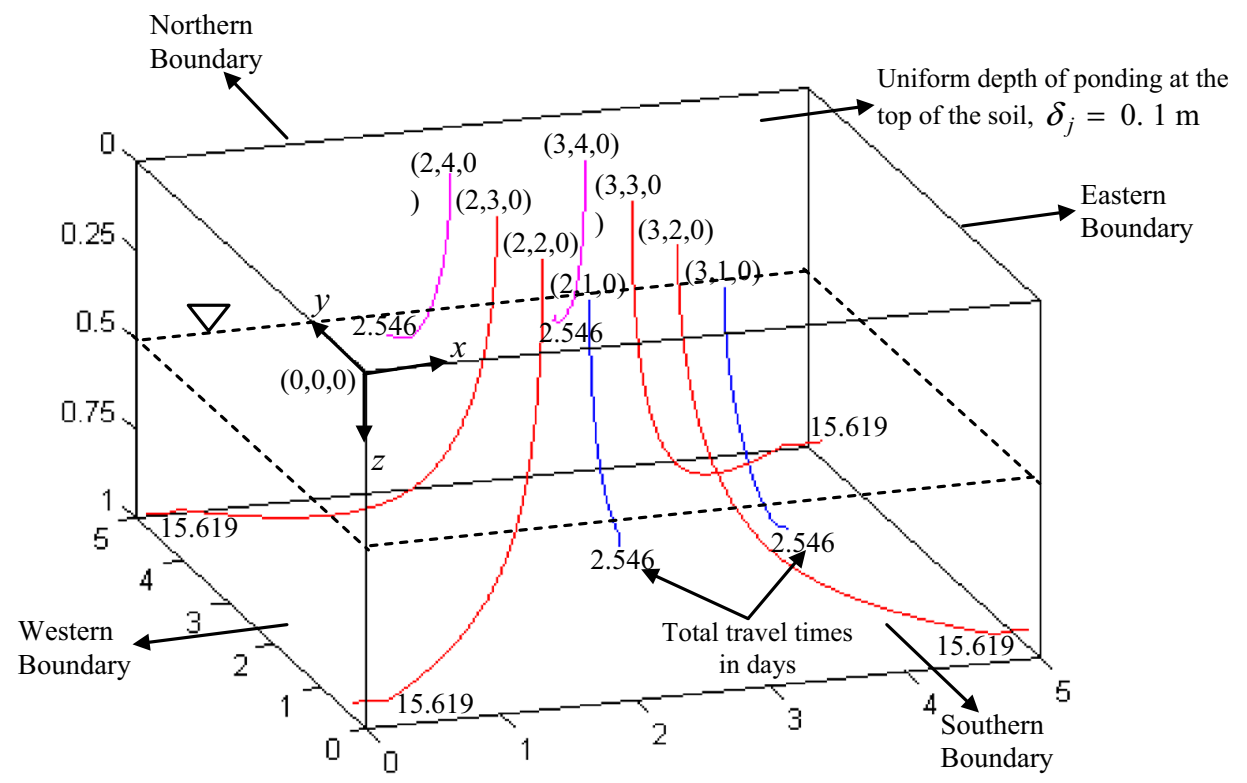

Figure 6. Travel times of water particles (in days) on a few pathlines starting from the surface of the soil to the recipient ditches under the steady state condition when the parameters of figure 1 are taken as $L=5 \mathrm{~m}, B=5 \mathrm{~m}, h=1 \mathrm{~m}, H_{2}=0.5 \mathrm{~m}, H_{1}=0.5 \mathrm{~m}, H_{3}=$ $0.5 \mathrm{~m}, H_{4}=0.5 \mathrm{~m}, \delta_{j}=0.1 \mathrm{~m}, \eta=0.3, K_{x}=K_{y}=1 \mathrm{~m} /$ day and $K_{z}=0.1 \mathrm{~m} /$ day.

here can also be utilized to design ditch drains for determining the upper limit of fall of water level of a waterlogged soil at the surface of a flooded field. Consider, for example, the flow situation as mentioned in figure 6; for this situation, the volume of water seeping from the surface of the soil in the first $1 \mathrm{~h}$ has turned out to be $0.1378 \mathrm{~m}^{3}$ and in the first $5 \mathrm{~h}$ to be $0.6924 \mathrm{~m}^{3}$. Thus, the upper limit of fall of water will be $5.738 \mathrm{~mm}$ at the end of the first hour and 


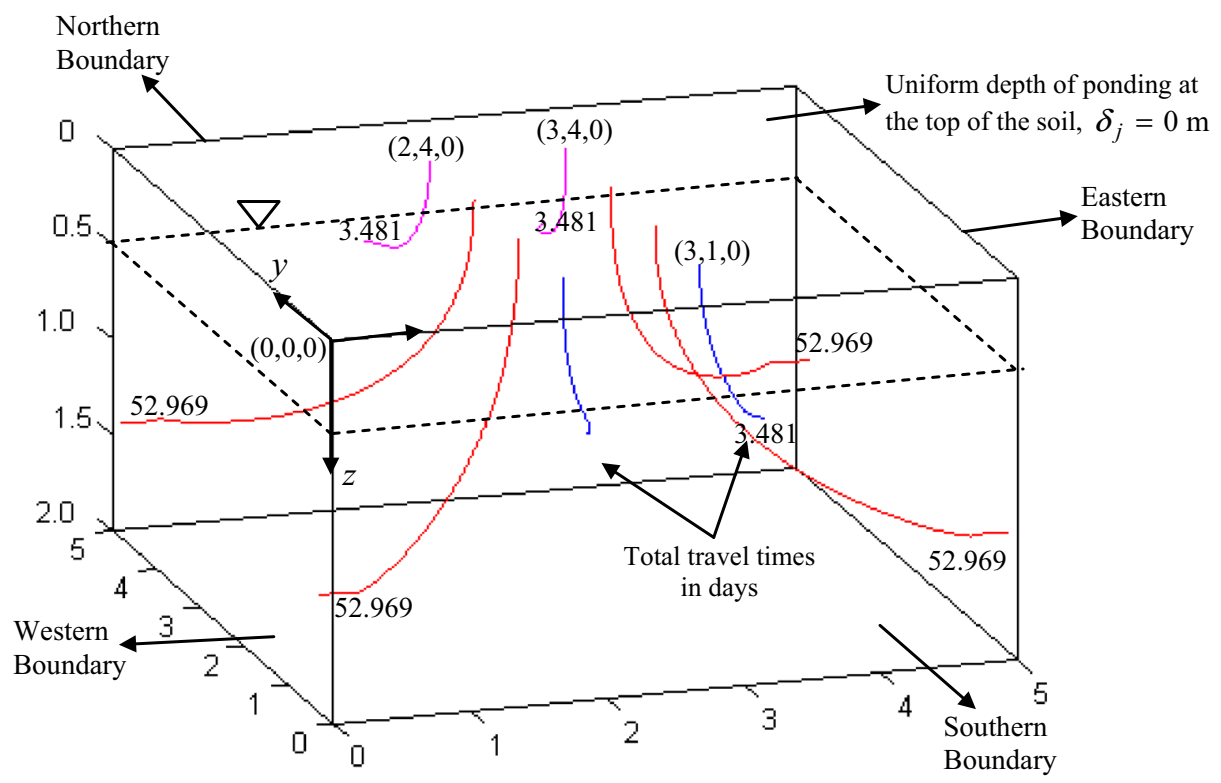

Figure 7. Travel times of water particles (in days) on a few pathlines starting from the surface of the soil to the recipient ditches under steady state condition when the parameters of figure 1 are taken as $L=5 \mathrm{~m}, B=5 \mathrm{~m}, h=2 \mathrm{~m}, H_{1}=0.5 \mathrm{~m}, H_{2}=0.5 \mathrm{~m}, H_{3}=0.5 \mathrm{~m}$, $H_{4}=0.5 \mathrm{~m}, \delta_{j}=0 \mathrm{~m}, \eta=0.3, K_{x}=K_{y}=1 \mathrm{~m} /$ day and $K_{z}=0.1 \mathrm{~m} /$ day.

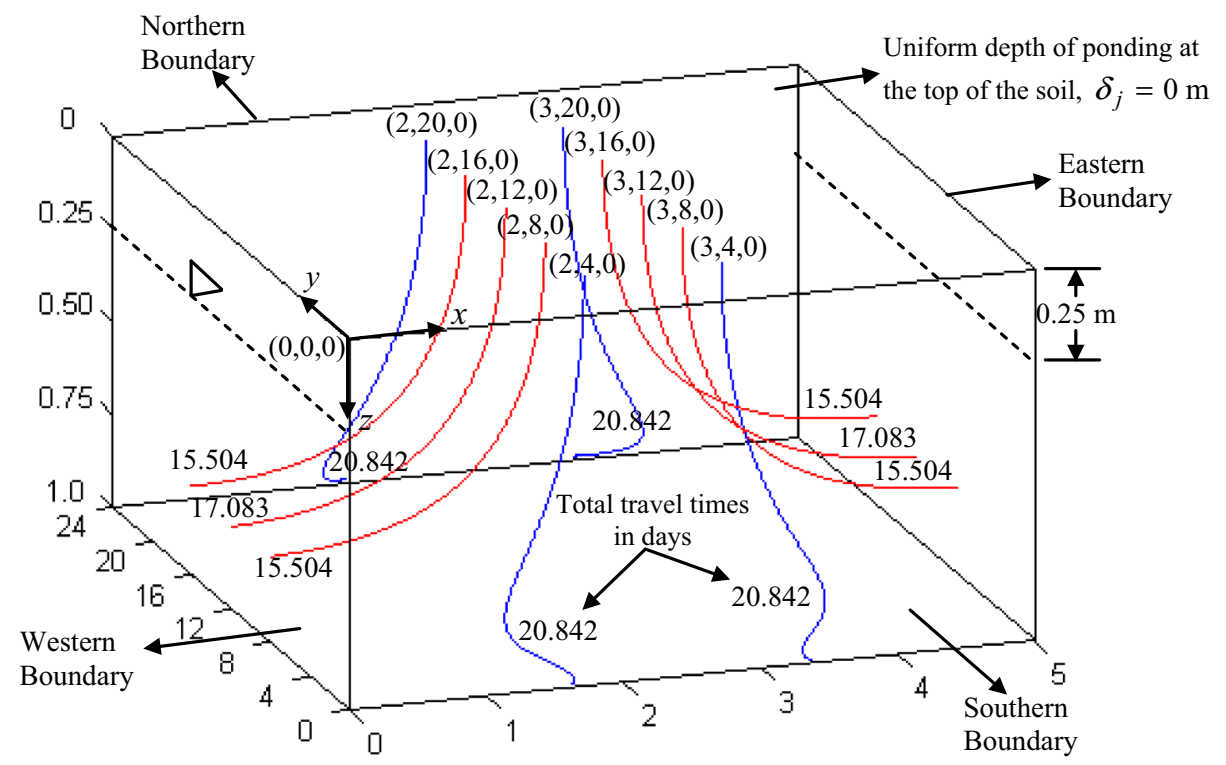

Figure 8. Travel times of water particles (in days) on a few pathlines starting from the surface of the soil to the recipient ditches under steady state condition when the parameters of figure 1 are taken as $L=5 \mathrm{~m}, B=24 \mathrm{~m}, h=1 \mathrm{~m}, H_{1}=1 \mathrm{~m}, H_{2}=1 \mathrm{~m}, H_{3}=0.25 \mathrm{~m}$, $H_{4}=0.25 \mathrm{~m}, \delta_{j}=0 \mathrm{~m}, \eta=0.3, K_{x}=K_{y}=1 \mathrm{~m} /$ day and $K_{z}=0.1 \mathrm{~m} / \mathrm{day}$.

$28.840 \mathrm{~mm}$ at the end of $5 \mathrm{~h}$. These values are upper limits of fall because while determining them it is intrinsically assumed that the depth of ponded water of $0.1 \mathrm{~m}$ over the surface of the soil remains constant throughout the simulation times. In reality, however, the depth of ponding, and hence the water-head over the surface of the soil, will fall with the increase of time, resulting in less volume of water seeping into the drains in a fixed time in comparison 
(a)

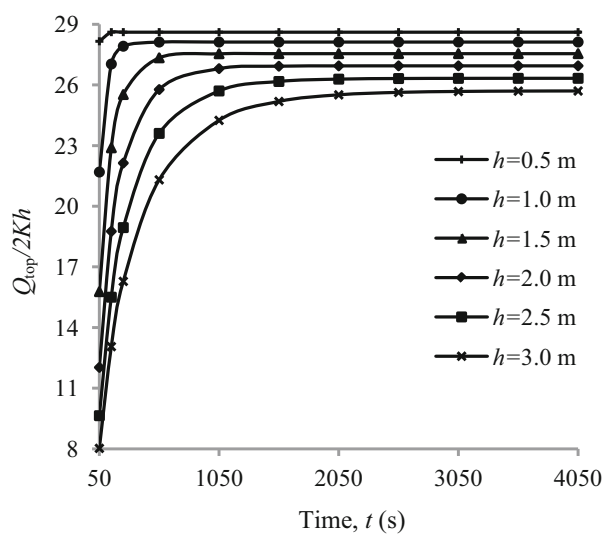

(c)

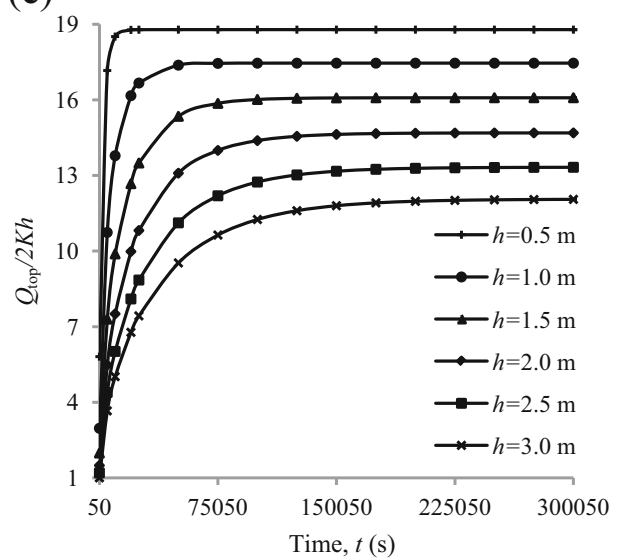

(b)

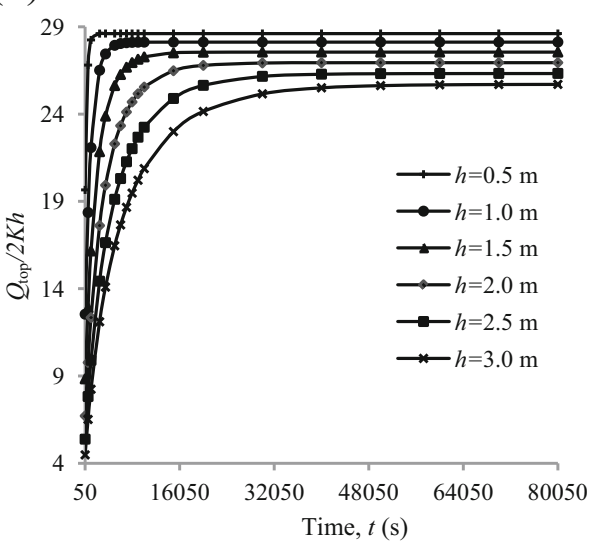

(d)

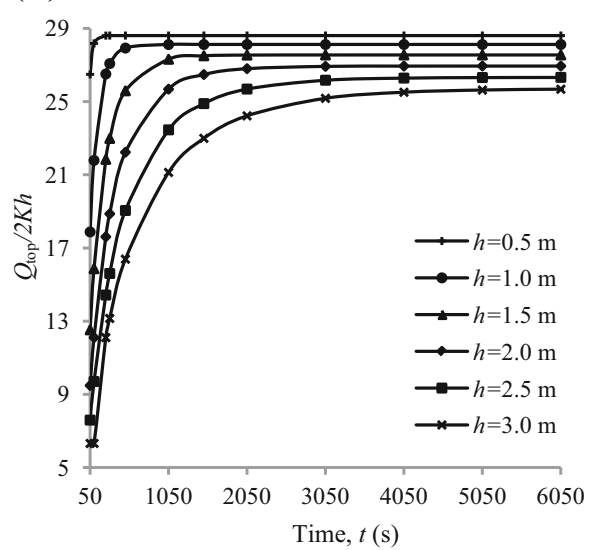

Figure 9. Variation of $Q_{\text {top }} / 2 K h$ ratio $\left[\right.$ where $\left.K=\left(K_{x} K_{y} K_{z}\right)^{1 / 3}\right]$ with time as obtained from the proposed analytical model for different values of $h$ (with $h=H_{1}=H_{2}=H_{3}=H_{4}$ i.e., ditches are running empty) when the parameters of figure 1 are taken as $L=20 \mathrm{~m}$, $B=20 \mathrm{~m}, \delta_{j}=0 \mathrm{~m}$, (a) $K_{x}=K_{y}=K_{z}=0.5 \mathrm{~m} /$ day, $S_{s}=0.001 \mathrm{~m}$, (b) $K_{x}=K_{y}=K_{z}=0.0254 \mathrm{~m} / \mathrm{day}, S_{s}=0.001 \mathrm{~m}$, (c) $K_{x}=K_{y}=$ $0.0254 \mathrm{~m} /$ day, $K_{z}=0.00254 \mathrm{~m} /$ day, $S_{s}=0.001 \mathrm{~m},(\mathbf{d}) K_{x}=K_{y}=K_{z}=0.0254 \mathrm{~m} /$ day, $S_{s}=0.0001 \mathrm{~m}$.

with the volume of water seeping into the drains as obtained using the constant ponding depth assumption. Nevertheless, an estimation of upper limit of fall of water level at the surface of a waterlogged soil via a ditch drainage system gives valuable information as it provides insight about the efficacy of the chosen drainage system in controlling surface waterlogging of the concerned soil profile.

\section{Conclusions}

An analytical solution has been developed for predicting three-dimensional transient seepage of water into ditch drains surrounding a horizontal, saturated, homogeneous and anisotropic soil medium being subjected to a variable ponding distribution at the surface of the soil. The solution has been based on the assumption of existence of a horizontal impervious barrier at a finite distance from the surface of the soil. The separation of the variable method in association with a careful mix of double and triple Fourier runs have been made use of to obtain solution to the considered problem. Double Fourier runs have been made for tackling the boundary conditions and the triple Fourier run has been made to negotiate the initial condition of the problem. The transient expressions for the hydraulic head, top and side discharges pertinent to the problem can be easily reduced to that of the steady state by simply allowing the time variable in them to go to infinity; this will make the exponential terms in them to disappear, living behind only the steady-state terms. The validity of the proposed solution has been checked for a few simplified situations by comparing predictions as obtained from the proposed solutions with the corresponding predictions obtained from 


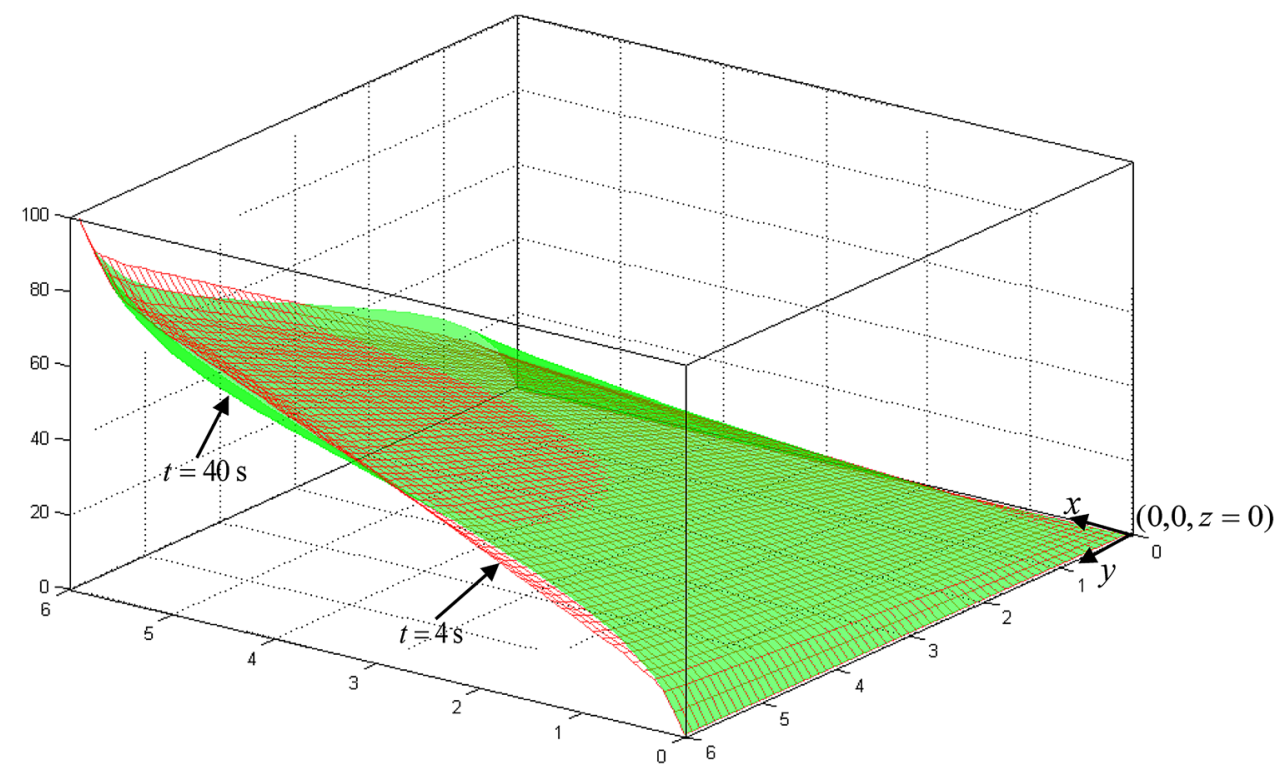

Figure 10. Variations of $Q_{\text {top }}^{n f}$ as obtained from the proposed analytical model for two different times $t=4 \mathrm{~s}$ and $t=40 \mathrm{~s}$ when the parameters of figure 1 are taken as $L=6 \mathrm{~m}, B=6 \mathrm{~m}, h=1 \mathrm{~m}, H_{1}=0.5 \mathrm{~m}, H_{2}=0.5 \mathrm{~m}, H_{3}=0.5 \mathrm{~m}, H_{4}=0.5 \mathrm{~m}, K_{x}=K_{y}=K_{z}=$ $1 \mathrm{~m} /$ day, $S_{s}=0.001 \mathrm{~m}, \delta_{j}=0.1 \mathrm{~m}, \varepsilon_{x}=0.05 \mathrm{~m}, \varepsilon_{y}=0.05 \mathrm{~m}$.

the analytical and experimental works of others. A numerical check on the developed model has also been carried out using the PMWIN platform.

The solution presented here is new and pretty comprehensive in nature in that it includes most of the leading parameters of the three-dimensional ditch drainage problem. Further, as stated before, this solution is valid for a field of actual size; this is in contrast with the existing twodimensional solutions of the problem, which, in the right sense, are actually valid for a field of infinite size only. From the study, it is clearly seen that flow to ditch drains from a ponded field is mostly three-dimensional in nature, particularly in areas lying close to the drains. Even for a ponded drainage situation where the separation between two of its opposite drainage boundaries is kept quite large, the three-dimensional nature of the pathlines can still prevail, again mainly in locations adjacent to the drains. However, on a parallel vertical plane lying further away from both the boundaries, two-dimensional flow situation can roughly be assumed without introducing any appreciable error in the hydraulics associated with this plane. It is also observed from the study that the time taken by a threedimensional ponded ditch drainage system to go to steady state may be considerable for a soil with low directional conductivities and high specific storage, particularly for situations where the ditches are installed relatively deeper into the ground. Further, the hydraulics associated with such a system has been observed to be sensitive to the spacing and water level heights of the ditches as well as on the nature and magnitude of the ponding field being imposed at the surface of the soil. It is seen that by just playing with the level of water in a ditch, noticeable changes to the distribution of pathlines in locations close to the ditch as well as to the overall discharge to the ditch can be brought about. This is an important observation as it demonstrates that the flow in a three-dimensional ditch drainage space can be visibly altered by just changing the water level heights of the drains. It has also come out of the study that by suitably playing with the ponding field at the surface of a ponded ditch drainage system, significant improvement in the uniformity of the distribution of the flow lines as well as on the water particle travel times along these flow lines can be achieved. This observation has significance since reclaiming a salt-affected soil by a ponded ditch drainage system by subjecting it to only a uniform ponding depth at the surface of the soil most often leads to uneven washing of the soil profile with the regions close to the drains over-washed and regions away from the drains under-washed. Further, as the model proposed here is of a general nature in the sense that it can accommodate threedimensional flows, variable ponding distributions and unequal water level heights of the drains, it is expected to provide better drainage solutions for cleaning salt-affected soils as compared with drainage solutions developed utilizing more stringent assumptions. The solution proposed here can also be used to design ditch drains for draining a waterlogged field by a desired amount at the surface within a stipulated time and is, thus, important from the point of view of reclamation of a flooded and waterlogged field as well. 

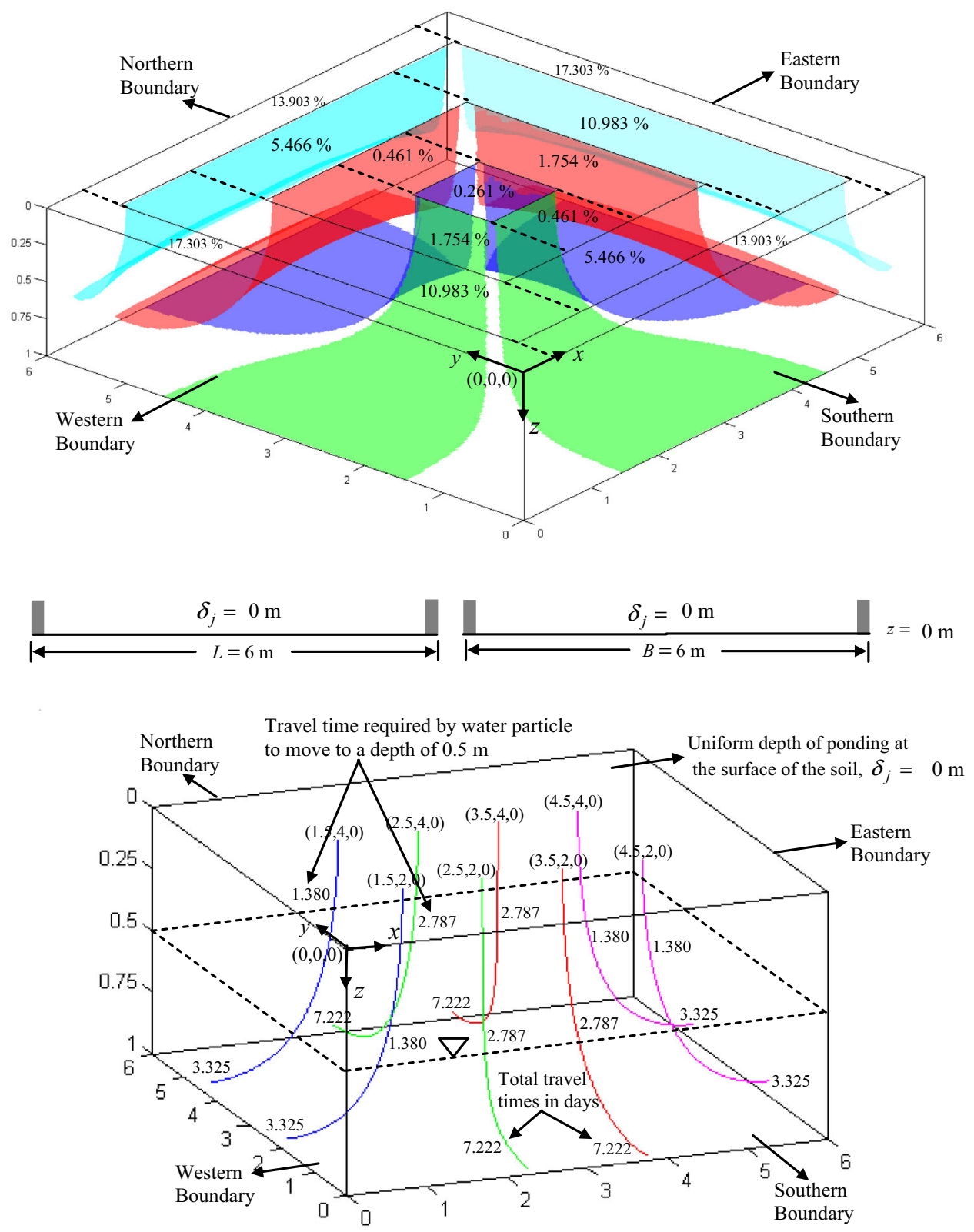

Figure 11. A few stream surfaces and travel times (in days) of water particle on a few pathlines starting from the surface of the soil when the parameters of figure 1 are taken as $L=6 \mathrm{~m}, B=6 \mathrm{~m}, h=1 \mathrm{~m}, H_{1}=0.5 \mathrm{~m}, H_{2}=0.5 \mathrm{~m}, H_{3}=0.5 \mathrm{~m}, H_{4}=0.5 \mathrm{~m}, K_{x}=$ $K_{y}=K_{z}=1 \mathrm{~m} /$ day, $\delta_{j}=0 \mathrm{~m}$. 

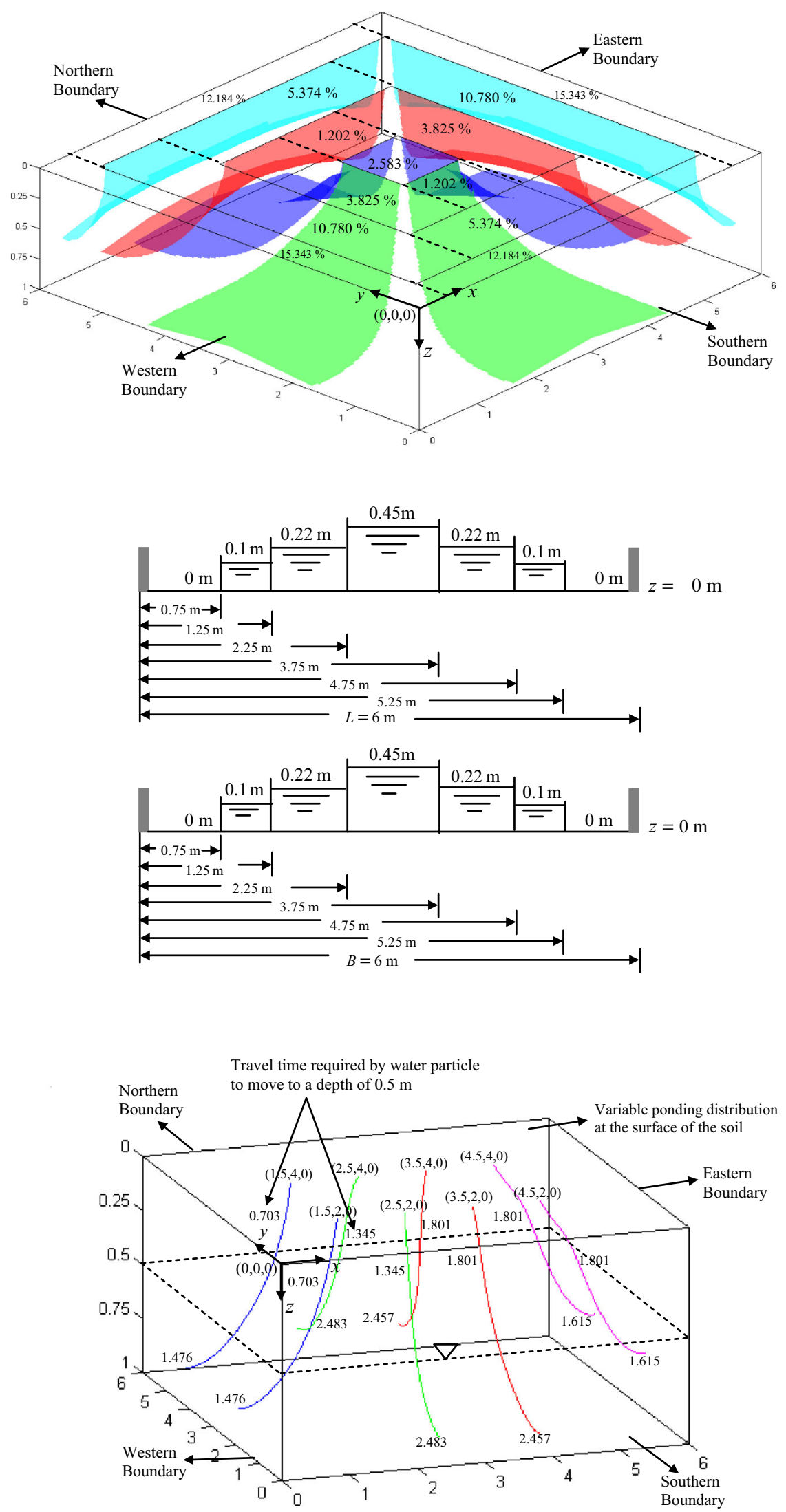
4Figure 12. A few stream surfaces and travel times (in days) of water particle on a few pathlines starting from the surface of the soil when the parameters of figure 1 are taken as $L=6 \mathrm{~m}, B=$ $6 \mathrm{~m}, h=1 \mathrm{~m}, H_{1}=0.5 \mathrm{~m}, H_{2}=0.5 \mathrm{~m}, H_{3}=0.5 \mathrm{~m}, H_{4}=$ $0.5 \mathrm{~m}, K_{x}=K_{y}=K_{z}=1 \mathrm{~m} /$ day, $d_{x 1}=0.75 \mathrm{~m}, d_{x 2}=1.25 \mathrm{~m}$, $d_{x 3}=2.25 \mathrm{~m}, d_{x 4}=3.75 \mathrm{~m}, d_{x 5}=4.75 \mathrm{~m}, d_{x 6}=5.25 \mathrm{~m}, d_{y 1}=$ $0.75 \mathrm{~m}, \quad d_{y 2}=1.25 \mathrm{~m}, \quad d_{y 3}=2.25 \mathrm{~m}, \quad d_{y 4}=3.75 \mathrm{~m}, \quad d_{y 5}=$ $4.75 \mathrm{~m}, \quad d_{y 6}=5.25 \mathrm{~m}, \quad \delta_{1}=0 \mathrm{~m}, \quad \delta_{2}=0.1 \mathrm{~m}, \quad \delta_{3}=0.22 \mathrm{~m}$, $\delta_{4}=0.45 \mathrm{~m}$.

\section{List of notations}

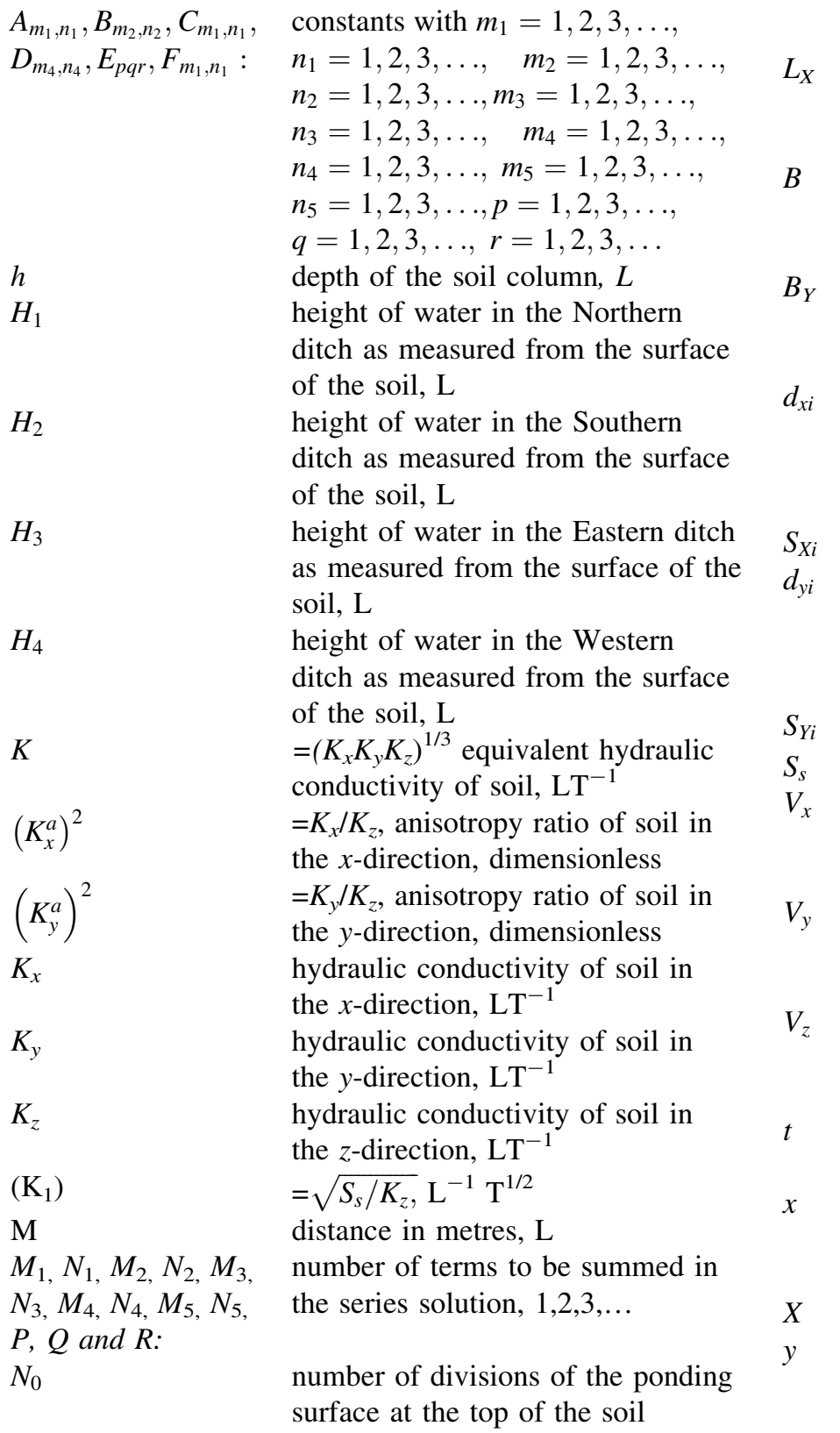

$Q_{N}, Q_{S}, Q_{E}, Q_{W}: \quad$ discharge through the Northern, Southern, Eastern, Western faces of the soil column of figure 1 , $\mathrm{L}^{3} \mathrm{~T}^{-1}$ top discharge function defined for the surface of the soil of figure 1 , $\mathrm{L}^{3} \mathrm{~T}^{-1}$

$Q_{\text {top }}$

$Q_{\text {top }}^{n f}$

$L$

$B_{Y}$

$d_{x i}$

$S_{X i}$ $d_{y i}$

$S_{s}$ $V_{x}$

$V_{y}$

$V_{z}$

discharge through the top surface of the soil of figure $1, \mathrm{~L}^{3} \mathrm{~T}^{-1}$ top discharge function expressed as a percentage of $Q_{\text {top }}$, dimensionless distance between the adjacent drains in the $x$-direction in the real space of figure $1, \mathrm{~L}$

distance between the adjacent drains in the $X$-direction in the computational space of figure $1, \mathrm{~L}$ distance between the adjacent drains in the $y$-direction in the real space of figure $1, \mathrm{~L}$

distance between the adjacent drains in the $Y$-direction in the computational space of figure $1, \mathrm{~L}$ distance of the ith $\left(1 \leq i \leq N_{0}-1\right)$ inner bund from the origin $O$ in the $x$-direction of figure 1 in the real space, $\mathrm{L}$

$=d_{x i} / K_{x}^{a}, \mathrm{~L}$

distance of the ith $\left(1 \leq i \leq N_{0}-1\right)$ inner bund from the origin $O$ in the $y$-direction of figure 1 in the real space, $\mathrm{L}$

$d_{y i} / K_{y}^{a}, \mathrm{~L}$

specific storage of soil, $\mathrm{L}^{-1}$

velocity distribution for the flow domain of figure 1 in the $x$-direction, $\mathrm{LT}^{-1}$

velocity distribution for the flow domain of figure 1 in the $y$-direction, $\mathrm{LT}^{-1}$

velocity distribution for the flow domain of figure 1 in the $z$-direction, $\mathrm{LT}^{-1}$

time variable for the flow problem of figure $1, \mathrm{~T}$

coordinate as measured from the origin $\mathrm{O}$ of figure 1 in the East-West dirction in the real space $=x / K_{x}^{a}, \mathrm{~L}$

coordinate as measured from the origin $\mathrm{O}$ of figure 1 in the North-South dirction in the real space 


$\begin{array}{ll}Y & =y / K_{y}^{a}, \mathrm{~L} \\ z & \begin{array}{l}\text { coordinate as measured from the } \\ \text { origin } \mathrm{O} \text { of figure } 1 \text { in the } \\ \text { downward direction in the real } \\ \text { space, } \mathrm{L}\end{array} \\ & \text { ponding depth at the } i \text { th segment } \\ & \text { on the surface of the soil, } \mathrm{L} \\ & \text { width of the ditch banks in the } \\ & x \text {-direction in the real space of } \\ \varepsilon_{x} & \text { figure } 1, \mathrm{~L} \\ & \text { width of the ditch banks in the } \\ & y \text {-direction in the real space of } \\ & \text { figure } 1, \mathrm{~L} \\ & \text { hydraulic head distribution for the } \\ & \text { flow domain of figure 1 } \\ & \text { (with th Northern boundary as a } \\ & \text { ditch drainage boundary), L }\end{array}$

\section{Appendix 1. Determination of coefficients of the hydraulic head function of Eq. (2)}

In this section, the coefficients appearing in Eq. (2) will be determined utilizing the appropriate initial and boundary value conditions mentioned in the definition of the problem. To evaluate $A_{m_{1} n_{1}}$, boundary conditions (IIIa) and (IIIb) can be made use of; application of the same to Eq. (2) at $Y=0$ gives

$$
\begin{aligned}
& \sum_{m_{1}=1}^{M_{1}} \sum_{n_{1}=1}^{N_{1}} A_{m_{1} n_{1}} \sin \left(N_{m_{1}} X\right) \sin \left(N_{n_{1}} z\right)=-z, \quad 0<X<L_{X}, \\
& 0<z<H_{2}, \\
& \sum_{m_{1}=1}^{M_{1}} \sum_{n_{1}=1}^{N_{1}} A_{m_{1} n_{1}} \sin \left(N_{m_{1}} X\right) \sin \left(N_{n_{1}} z\right)=-H_{2}, \quad 0<X<L_{X}, \\
& \quad H_{2} \leq z<h .
\end{aligned}
$$

Thus, $A_{m_{1} n_{1}}$ can be evaluated by running a double Fourier series in the domain covered by $0<X<L_{X}$ and $0<z<h$; this yields an expression for $A_{m_{1} n_{1}}$ as

$$
\begin{aligned}
A_{m_{1} n_{1}}= & -\left(\frac{2}{L_{x}}\right)\left(\frac{2}{h}\right)\left[\int_{0}^{L_{X}} \int_{0}^{H_{2}} z \sin \left(N_{m_{1}} X\right) \sin \left(N_{n_{1}} z\right) d X d z\right. \\
& \left.+\int_{0}^{L_{X}} \int_{H_{2}}^{h} H_{2} \sin \left(N_{m_{1}} X\right) \sin \left(N_{n_{1}} z\right) d X d z\right] . .
\end{aligned}
$$

Simplification of the above integrals yields

$$
A_{m_{1} n_{1}}=-\left(\frac{2}{L_{x}}\right)\left(\frac{2}{h}\right)\left[\frac{1-\cos \left(N_{m_{1}} L_{X}\right)}{N_{m_{1}}}\right]\left[\frac{\sin \left(N_{n_{1}} H_{2}\right)}{\left(N_{n_{1}}\right)^{2}}\right] .
$$

Similarly, an application of boundary conditions (IIa) and (IIb) to Eq. (2) gives $B_{m_{2} n_{2}}$ as

$$
B_{m_{2} n_{2}}=-\left(\frac{2}{L_{x}}\right)\left(\frac{2}{h}\right)\left[\frac{1-\cos \left(N_{m_{2}} L_{X}\right)}{N_{m_{2}}}\right]\left[\frac{\sin \left(N_{n_{2}} H_{1}\right)}{\left(N_{n_{2}}\right)^{2}}\right] .
$$

Likewise, boundary conditions ( $\mathrm{Va}$ ) and ( $\mathrm{Vb}$ ) and (IVa) and (IVb) can be utilized to evaluate the constants $C_{m_{3} n_{3}}$ and $D_{m_{4} n_{4}}$ of Eq. (2); the relevant expressions for the same can be expressed as

$$
C_{m_{3} n_{3}}=-\left(\frac{2}{B_{Y}}\right)\left(\frac{2}{h}\right)\left[\frac{1-\cos \left(N_{m_{3}} B_{Y}\right)}{N_{m_{3}}}\right]\left[\frac{\sin \left(N_{n_{3}} H_{4}\right)}{\left(N_{n_{3}}\right)^{2}}\right]
$$

and

$$
D_{m_{4} n_{4}}=-\left(\frac{2}{B_{Y}}\right)\left(\frac{2}{h}\right)\left[\frac{1-\cos \left(N_{m_{4}} B_{Y}\right)}{N_{m_{4}}}\right]\left[\frac{\sin \left(N_{n_{4}} H_{3}\right)}{\left(N_{n_{4}}\right)^{2}}\right] .
$$

Next, to work out the constants $F_{m_{5} n_{5}}$ of Eq. (2), boundary conditions (VIIa) to (VIIj) can be made use of; applying the same to Eq. (2), the following set of equations can be realized:

$$
\begin{aligned}
& \sum_{m_{5}=1}^{M_{5}} \sum_{n_{5}=1}^{N_{5}} F_{m_{5} n_{5}} \sin \left(N_{m_{5}} X\right) \sin \left(N_{n_{5}} Y\right)=\delta_{1}, \quad 0<X<L_{X}, \\
& 0<Y<S_{Y 1}, \quad z=0, \\
& \sum_{m_{5}=1}^{M_{5}} \sum_{n_{5}=1}^{N_{5}} F_{m_{5} n_{5}} \sin \left(N_{m_{5}} X\right) \sin \left(N_{n_{5}} Y\right)=\delta_{1}, \quad 0<X<L_{X}, \\
& S_{Y\left(2 N_{0}-2\right)}<Y<B_{Y}, \quad z=0, \\
& \sum_{m_{5}=1}^{M_{5}} \sum_{n_{5}=1}^{N_{5}} F_{m_{5} n_{5}} \sin \left(N_{m_{5}} X\right) \sin \left(N_{n_{5}} Y\right)=\delta_{1}, \quad 0<X<S_{X 1}, \\
& S_{Y 1}<Y<S_{Y\left(2 N_{0}-2\right)}, \quad z=0, \\
& \sum_{m_{5}=1}^{M_{5}} \sum_{n_{5}=1}^{N_{5}} F_{m_{5} n_{5}} \sin \left(N_{m_{5}} X\right) \sin \left(N_{n_{5}} Y\right)=\delta_{1}, \\
& S_{X\left(2 N_{0}-2\right)}<X<L_{X}, \quad S_{Y 1}<Y<S_{Y\left(2 N_{0}-2\right)}, \quad z=0, \\
& \sum_{m_{5}=1}^{M_{5}} \sum_{n_{5}=1}^{N_{5}} F_{m_{5} n_{5}} \sin \left(N_{m_{5}} X\right) \sin \left(N_{n_{5}} Y\right)=\delta_{j}, \\
& S_{X(j-1)}<X<S_{X\left(2 N_{0}-j\right)}, \quad S_{Y(j-1)}<Y<S_{Y j}, \quad z=0, \\
& \sum_{m_{5}=1}^{M_{5}} \sum_{n_{5}=1}^{N_{5}} F_{m_{5} n_{5}} \sin \left(N_{m_{5}} X\right) \sin \left(N_{n_{5}} Y\right)=\delta_{j}, \\
& S_{X(j-1)}<X<S_{X\left(2 N_{0}-j\right)}, \quad S_{Y\left(2 N_{0}-j-1\right)}<Y<S_{Y\left(2 N_{0}-j\right)}, \\
& z=0,
\end{aligned}
$$




$$
\begin{aligned}
& \sum_{m_{5}=1}^{M_{5}} \sum_{n_{5}=1}^{N_{5}} F_{m_{5} n_{5}} \sin \left(N_{m_{5}} X\right) \sin \left(N_{n_{5}} Y\right)=\delta_{j}, \\
& S_{X(j-1)}<X<S_{X j}, \quad S_{Y j}<Y<S_{Y\left(2 N_{0}-j-1\right)}, \quad z=0 \\
& \sum_{m_{5}=1}^{M_{5}} \sum_{n_{5}=1}^{N_{5}} F_{m_{5} n_{5}} \sin \left(N_{m_{5}} X\right) \sin \left(N_{n_{5}} Y\right)=\delta_{j}, \\
& \quad S_{X\left(2 N_{0}-j-1\right)}<X<S_{X\left(2 N_{0}-j\right)}, \quad S_{Y j}<Y<S_{Y\left(2 N_{0}-j-1\right)}, \\
& \quad z=0
\end{aligned}
$$

$$
\left(2 \leq j \leq N_{0}-1\right)
$$$$
\sum_{m_{5}=1}^{M_{5}} \sum_{n_{5}=1}^{N_{5}} F_{m_{5} n_{5}} \sin \left(N_{m_{5}} X\right) \sin \left(N_{n_{5}} Y\right)=\delta_{N_{0}},
$$$$
S_{X\left(N_{0}-1\right)}<X<S_{X N_{0}}, \quad S_{Y\left(N_{0}-1\right)}<Y<S_{Y N_{0}}, \quad z=0,
$$

where

$$
S_{X i}=\left(\sqrt{\frac{K_{z}}{K_{x}}}\right) d_{x i}
$$

and

$$
S_{Y i}=\left(\sqrt{\frac{K_{z}}{K_{y}}}\right) d_{y i}, \quad\left[i=1,2,3, \ldots,\left(2 N_{0}-2\right)\right]
$$

Thus, $F_{m_{5} n_{5}}$ can be evaluated by running a double Fourier series in the space defined by the intervals $0<X<L_{X}$ and $0<Y<B_{Y}$; this yields an equation for evaluating $F_{m_{5} n_{5}}$ as

$$
\begin{aligned}
& F_{m_{5} n_{5}}=\left(\frac{2}{B_{Y}}\right)\left(\frac{2}{L_{X}}\right)\left\{\delta _ { 1 } \left[\int_{0}^{L_{X}} \int_{0}^{S_{Y 1}} \sin \left(N_{m_{5}} X\right) \sin \left(N_{n_{5}} Y\right) d X d Y\right.\right. \\
& +\int_{0}^{L_{X}} \int_{S_{Y\left(2 N_{0}-2\right)}}^{B_{Y}} \sin \left(N_{m_{5}} X\right) \sin \left(N_{n_{5}} Y\right) d X d Y \\
& +\int_{0}^{S_{X 1}} \int_{S_{Y 1}}^{S_{Y\left(2 N_{0}-2\right)}} \sin \left(N_{m_{5}} X\right) \sin \left(N_{n_{5}} Y\right) d X d Y \\
& \left.+\int_{S_{X\left(2 N_{0}-2\right)}}^{L_{X}} \int_{S_{Y 1}}^{S_{Y\left(2 N_{0}-2\right)}} \sin \left(N_{m_{5}} X\right) \sin \left(N_{n_{5}} Y\right) d X d Y\right] \\
& +\sum_{j=2}^{j=N_{0}-1} \delta_{j}\left[\int_{S_{X(j-1)}}^{S_{X\left(2 N_{0}-j\right)}} \int_{S_{Y(j-1)}}^{S_{Y j}} \sin \left(N_{m_{5}} X\right) \sin \left(N_{n_{5}} Y\right) d X d Y\right. \\
& +\int_{S_{X(j-1)}}^{S_{X\left(2 N_{0}-j\right)}} \int_{S_{Y\left(2 N_{0}-j-1\right)}}^{S_{Y\left(2 N_{0}-j\right)}} \sin \left(N_{m_{5}} X\right) \sin \left(N_{n_{5}} Y\right) d X d Y
\end{aligned}
$$

$$
\begin{aligned}
& +\int_{S_{X(j-1)}}^{S_{X j}} \int_{S_{Y j}}^{S_{Y\left(2 N_{0}-j-1\right)}} \sin \left(N_{m_{5}} X\right) \sin \left(N_{n_{5}} Y\right) d X d Y \\
& \left.+\int_{S_{X\left(2 N_{0}-j-1\right)}}^{S_{X\left(2 N_{0}-j\right)}} \int_{S_{Y j}}^{S_{Y\left(2 N_{0}-j-1\right)}} \sin \left(N_{m_{5}} X\right) \sin \left(N_{n_{5}} Y\right) d X d Y\right] \\
& \left.+\delta_{N_{0}} \int_{S_{X\left(N_{0}-1\right)}}^{S_{S_{Y N}}^{S_{Y N_{0}}}} \sin \left(N_{m_{5}} X\right) \sin \left(N_{n_{5}} Y\right) d X d Y\right\}
\end{aligned}
$$

Simplification of the above integrals gives an expression for $F_{m_{5} n_{5}}$ as

$$
\begin{aligned}
& F_{m_{5} n_{5}}=\left(\frac{2}{B_{Y}}\right)\left(\frac{2}{L_{X}}\right)\left\{\delta _ { 1 } \left[\left(\frac{1-\cos \left(N_{m_{5}} L_{X}\right)}{N_{m_{5}}}\right)\right.\right. \\
& \times\left[\frac{1-\cos \left(N_{n_{5}} S_{Y 1}\right)}{N_{n_{5}}}+\frac{\cos \left(N_{n_{5}} S_{Y\left(2 N_{0}-2\right)}\right)-\cos \left(N_{n_{5}} B_{Y}\right)}{N_{n_{5}}}\right] \\
& +\left(\frac{\cos \left(N_{n_{5}} S_{Y 1}\right)-\cos \left(N_{n_{5}} S_{Y\left(2 N_{0}-2\right)}\right)}{N_{n_{5}}}\right) \\
& \left.\times\left[\frac{1-\cos \left(N_{m_{5}} S_{X 1}\right)}{N_{m_{5}}}+\frac{\cos \left(N_{m_{5}} S_{X\left(2 N_{0}-2\right)}\right)-\cos \left(N_{m_{5}} L_{X}\right)}{N_{m_{5}}}\right]\right] \\
& +\sum_{j=2}^{j=N_{0}-1} \delta_{j}\left[\left(\frac{\cos \left(N_{m_{5}} S_{X(j-1)}\right)-\cos \left(N_{m_{5}} S_{X\left(2 N_{0}-j\right)}\right)}{N_{m_{5}}}\right)\right] \\
& \times\left[\frac{\cos \left(N_{n_{5}} S_{Y(j-1)}\right)-\cos \left(N_{n_{5}} S_{Y j}\right)}{N_{n_{5}}}\right. \\
& \left.+\frac{\cos \left(N_{n_{5}} S_{Y\left(2 N_{0}-j-1\right)}\right)-\cos \left(N_{n_{5}} S_{Y\left(2 N_{0}-j\right)}\right)}{N_{n_{5}}}\right] \\
& +\left(\frac{\cos \left(N_{n_{5}} S_{Y j}\right)-\cos \left(N_{n_{5}} S_{Y\left(2 N_{0}-j-1\right)}\right)}{N_{n_{5}}}\right) \\
& \times\left[\frac{\cos \left(N_{m_{5}} S_{X(j-1)}\right)-\cos \left(N_{m_{5}} S_{X j}\right)}{N_{m_{5}}}\right. \\
& \left.\left.+\frac{\cos \left(N_{m_{5}} S_{X\left(2 N_{0}-j-1\right)}\right)-\cos \left(N_{m_{5}} S_{X\left(2 N_{0}-j\right)}\right)}{N_{m_{5}}}\right]\right] \\
& +\delta_{N_{0}}\left[\frac{\cos \left(N_{m_{5}} S_{X\left(N_{0}-1\right)}\right)-\cos \left(N_{m_{5}} S_{X N_{0}}\right)}{N_{m_{5}}}\right. \\
& \left.\left.\times \frac{\cos \left(N_{n_{5}} S_{Y\left(N_{0}-1\right)}\right)-\cos \left(N_{n_{5}} S_{Y N_{0}}\right)}{N_{n_{5}}}\right]\right\} .
\end{aligned}
$$

There still remain the constants $E_{p q r}$ to be determined. Towards this end, the initial condItion (I) can be applied to Eq. (2); the pertinent expression for evaluating these constants can then be expressed as 
$\sum_{p=1}^{P} \sum_{q=1}^{Q} \sum_{r=1}^{R} E_{p q r} \sin \left(N_{p} X\right) \sin \left(N_{q} Y\right) \sin \left(N_{r} z\right)$

$=-\sum_{m_{1}=1}^{M_{1}} \sum_{n_{1}=1}^{N_{1}} A_{m_{1} n_{1}} \frac{\sinh \left[\sqrt{\left(N_{m_{1}}\right)^{2}+\left(N_{n_{1}}\right)^{2}}\left(B_{Y}-Y\right)\right]}{\sinh \left[\sqrt{\left(N_{m_{1}}\right)^{2}+\left(N_{n_{1}}\right)^{2}} B_{Y}\right]} \sin \left(N_{m_{1}} X\right) \sin \left(N_{n_{1}} z\right)$

$-\sum_{m_{2}=1}^{M_{2}} \sum_{n_{2}=1}^{N_{2}} B_{m_{2} n_{2}} \frac{\sinh \left[\sqrt{\left(N_{m_{2}}\right)^{2}+\left(N_{n_{2}}\right)^{2}} Y\right]}{\sinh \left[\sqrt{\left(N_{m_{2}}\right)^{2}+\left(N_{n_{2}}\right)^{2}} B_{Y}\right]} \sin \left(N_{m_{2}} X\right) \sin \left(N_{n_{2}} z\right)$

$-\sum_{m_{3}=1}^{M_{3}} \sum_{n_{3}=1}^{N_{3}} C_{m_{3} n_{3}} \frac{\sinh \left[\sqrt{\left(N_{m_{3}}\right)^{2}+\left(N_{n_{3}}\right)^{2}}\left(L_{X}-X\right)\right]}{\sinh \left[\sqrt{\left(N_{m_{3}}\right)^{2}+\left(N_{n_{3}}\right)^{2}} L_{X}\right]} \sin \left(N_{m_{3}} Y\right) \sin \left(N_{n_{3}} z\right)$

$-\sum_{m_{4}=1}^{M_{4}} \sum_{n_{4}=1}^{N_{4}} D_{m_{4} n_{4}} \frac{\sinh \left[\sqrt{\left(N_{m_{4}}\right)^{2}+\left(N_{n_{4}}\right)^{2}} X\right]}{\sinh \left[\sqrt{\left(N_{m_{4}}\right)^{2}+\left(N_{n_{4}}\right)^{2}} L_{X}\right]} \sin \left(N_{m_{4}} Y\right) \sin \left(N_{n_{4}} z\right)$

$-\sum_{m_{5}=1}^{M_{5}} \sum_{n_{5}=1}^{N_{5}} F_{m_{5} n_{5}} \frac{\cosh \left[\sqrt{\left(N_{m_{5}}\right)^{2}+\left(N_{n_{5}}\right)^{2}}(h-z)\right]}{\cosh \left[\sqrt{\left(N_{m_{5}}\right)^{2}+\left(N_{n_{5}}\right)^{2}} h\right]} \sin \left(N_{m_{5}} X\right) \sin \left(N_{n_{5}} Y\right)$.

Now, performing a triple Fourier run in the space defined by the intervals $0<X<L_{X}, 0<Y<B_{Y}$ and $0<z<h$, an expression for the constants $E_{p q r}$ can then be worked out as

$E_{p q r}=-\left(\frac{2}{L_{X}}\right)\left(\frac{2}{B_{Y}}\right)\left(\frac{2}{h}\right)$

$\left\{\int_{0}^{L_{X}} \int_{0}^{B_{Y}} \int_{0}^{h} \sum_{m_{1}=1}^{M_{1}} \sum_{n_{1}=1}^{N_{1}} A_{m_{1} n_{1}} \frac{\sinh \left[\sqrt{\left(N_{m_{1}}\right)^{2}+\left(N_{n_{1}}\right)^{2}}\left(B_{Y}-Y\right)\right]}{\sinh \left[\sqrt{\left(N_{m_{1}}\right)^{2}+\left(N_{n_{1}}\right)^{2}} B_{Y}\right]}\right.$

$\times \sin \left(N_{m_{1}} X\right) \sin \left(N_{n_{1}} z\right) \sin \left(N_{p} X\right) \sin \left(N_{q} Y\right) \sin \left(N_{r} z\right) d X d Y d z$

$+\int_{0}^{L_{X}} \int_{0}^{B_{Y}} \int_{0}^{h} \sum_{m_{2}=1}^{M_{2}} \sum_{n_{2}=1}^{N_{2}} B_{m_{2} n_{2}} \frac{\sinh \left[\sqrt{\left(N_{m_{2}}\right)^{2}+\left(N_{n_{2}}\right)^{2}} Y\right]}{\sinh \left[\sqrt{\left(N_{m_{2}}\right)^{2}+\left(N_{n_{2}}\right)^{2}} B_{Y}\right]}$

$\times \sin \left(N_{m_{2}} X\right) \sin \left(N_{n_{2}} z\right) \sin \left(N_{p} X\right) \sin \left(N_{q} Y\right) \sin \left(N_{r} z\right) d X d Y d z$

$+\int_{0}^{L_{X}} \int_{0}^{B_{Y}} \int_{0}^{h} \sum_{m_{3}=1}^{M_{3}} \sum_{n_{3}=1}^{N_{3}} C_{m_{3} n_{3}} \frac{\sinh \left[\sqrt{\left(N_{m_{3}}\right)^{2}+\left(N_{n_{3}}\right)^{2}}\left(L_{X}-X\right)\right]}{\sinh \left[\sqrt{\left(N_{m_{3}}\right)^{2}+\left(N_{n_{3}}\right)^{2}} L_{X}\right]}$

$\times \sin \left(N_{m_{3}} Y\right) \sin \left(N_{n_{3}} z\right) \sin \left(N_{p} X\right) \sin \left(N_{q} Y\right) \sin \left(N_{r} z\right) d X d Y d z$

$+\int_{0}^{L_{X}} \int_{0}^{B_{Y}} \int_{0}^{h} \sum_{m_{4}=1}^{M_{4}} \sum_{n_{4}=1}^{N_{4}} D_{m_{4} n_{4}} \frac{\sinh \left[\sqrt{\left(N_{m_{4}}\right)^{2}+\left(N_{n_{4}}\right)^{2}} X\right]}{\sinh \left[\sqrt{\left(N_{m_{4}}\right)^{2}+\left(N_{n_{4}}\right)^{2}} L_{X}\right]}$

$\times \sin \left(N_{m_{4}} Y\right) \sin \left(N_{n_{4}} z\right) \sin \left(N_{p} X\right) \sin \left(N_{q} Y\right) \sin \left(N_{r} z\right) d X d Y d z$

$+\int_{0}^{L_{X}} \int_{0}^{B_{Y}} \int_{0}^{h} \sum_{m_{5}=1}^{M_{5}} \sum_{n_{5}=1}^{N_{5}} F_{m_{5} n_{5}} \frac{\cosh \left[\sqrt{\left(N_{m_{5}}\right)^{2}+\left(N_{n_{5}}\right)^{2}}(h-z)\right]}{\cosh \left[\sqrt{\left(N_{m_{5}}\right)^{2}+\left(N_{n_{5}}\right)^{2}} h\right]}$

$\left.\times \sin \left(N_{m_{5}} X\right) \sin \left(N_{n_{5}} Y\right) \sin \left(N_{p} X\right) \sin \left(N_{q} Y\right) \sin \left(N_{r} z\right) d X d Y d z\right\}$.
Identifying the first, second, third, fourth and fifth tripleintegrals of Eq. (41) as $I^{(1)}, I^{(2)}, I^{(3)}, I^{(4)}$ and $I^{(5)}$, respectively, and then simplifying them yields an expression for $E_{p q r}$ as

$$
E_{p q r}=-\left(\frac{2}{L_{X}}\right)\left(\frac{2}{B_{Y}}\right)\left(\frac{2}{h}\right)\left[I^{(1)}+I^{(2)}+I^{(3)}+I^{(4)}+I^{(5)}\right],
$$

where

$$
I^{(1)}=\sum_{m_{1}=1}^{M_{1}} \sum_{n_{1}=1}^{N_{1}} A_{m_{1} n_{1}} I_{a}^{(1)} I_{b}^{(1)} I_{c}^{(1)} .
$$

For $N_{m_{1}}=N_{p}$

$$
I_{a}^{(1)}=\frac{L_{X}}{2}
$$

and for $N_{m_{1}} \neq N_{p}$

$$
\begin{gathered}
I_{a}^{(1)}=0, \\
I_{b}^{(1)}=\frac{N_{q}}{\left(N_{m_{1}}\right)^{2}+\left(N_{n_{1}}\right)^{2}+\left(N_{q}\right)^{2}} .
\end{gathered}
$$

For $N_{n_{1}}=N_{r}$

$$
I_{c}^{(1)}=\frac{h}{2}
$$

and for $N_{n_{1}} \neq N_{r}$

$$
\begin{gathered}
I_{c}^{(1)}=0 . \\
I^{(2)}=\sum_{m_{2}=1}^{M_{2}} \sum_{n_{2}=1}^{N_{2}} B_{m_{2} n_{2}} I_{a}^{(2)} I_{b}^{(2)} I_{c}^{(2)} .
\end{gathered}
$$

For $N_{m_{2}}=N_{p}$

$$
I_{a}^{(2)}=\frac{L_{X}}{2}
$$

and for $N_{m_{2}} \neq N_{p}$

$$
\begin{gathered}
I_{a}^{(2)}=0, \\
I_{b}^{(2)}=-\frac{N_{q} \cos \left(N_{q} B_{Y}\right)}{\left(N_{m_{2}}\right)^{2}+\left(N_{n_{2}}\right)^{2}+\left(N_{q}\right)^{2}} .
\end{gathered}
$$

For $N_{n_{2}}=N_{r}$

$$
I_{c}^{(2)}=\frac{h}{2}
$$

and for $N_{n_{2}} \neq N_{r}$

$$
I_{c}^{(2)}=0 .
$$




$$
I^{(3)}=\sum_{m_{3}=1}^{M_{3}} \sum_{n_{3}=1}^{N_{3}} C_{m_{3} n_{3}} I_{a}^{(3)} I_{b}^{(3)} I_{c}^{(3)},
$$

where

$$
I_{a}^{(3)}=\frac{N_{p}}{\left(N_{m_{3}}\right)^{2}+\left(N_{n_{3}}\right)^{2}+\left(N_{p}\right)^{2}} .
$$

For $N_{m_{3}}=N_{q}$

$$
I_{b}^{(3)}=\frac{B_{Y}}{2}
$$

and for $N_{m_{3}} \neq N_{q}$

$$
I_{3}^{(b)}=0
$$

For $N_{n_{3}}=N_{r}$

$$
I_{c}^{(3)}=\frac{h}{2}
$$

and for $N_{n_{3}} \neq N_{r}$

$$
\begin{gathered}
I_{c}^{(3)}=0 . \\
I^{(4)}=\sum_{m_{4}=1}^{M_{4}} \sum_{n_{4}=1}^{N_{4}} D_{m_{4} n_{4}} I_{a}^{(4)} I_{b}^{(4)} I_{c}^{(4)},
\end{gathered}
$$

where

$$
I_{a}^{(4)}=-\frac{N_{p} \cos \left(N_{p} L_{X}\right)}{\left(N_{m_{4}}\right)^{2}+\left(N_{n_{4}}\right)^{2}+\left(N_{p}\right)^{2}} .
$$

For $N_{m_{4}}=N_{q}$

$$
I_{b}^{(4)}=\frac{B_{Y}}{2}
$$

and for $N_{m_{4}} \neq N_{q}$

$$
I_{b}^{(4)}=0 .
$$

For $N_{n_{4}}=N_{r}$

$$
I_{c}^{(4)}=\frac{h}{2}
$$

and for $N_{n_{4}} \neq N_{r}$

$$
\begin{gathered}
I_{c}^{(4)}=0 . \\
I^{(5)}=\sum_{m_{5}=1}^{M_{5}} \sum_{n_{5}=1}^{N_{5}} F_{m_{5} n_{5}} I_{a}^{(5)} I_{b}^{(5)} I_{c}^{(5)},
\end{gathered}
$$

where for $N_{m_{5}}=N_{p}$

$$
I_{a}^{(5)}=\frac{L_{X}}{2}
$$

and for $N_{m_{5}} \neq N_{p}$

$$
I_{a}^{(5)}=0 .
$$

For $N_{n_{5}}=N_{q}$

$$
I_{b}^{(5)}=\frac{B_{Y}}{2}
$$

and for $N_{n_{5}} \neq N_{q}$

$$
I_{b}^{(5)}=0
$$

and

$$
I_{c}^{(5)}=\frac{N_{r}}{\left(N_{m_{5}}\right)^{2}+\left(N_{n_{5}}\right)^{2}+\left(N_{r}\right)^{2}} .
$$

All the coefficients of Eq. (2) are thus determined and the boundary value problem of figure 1 hence stands solved.

Further, like in the determination of the top discharge function, Darcy's law can also be applied to evaluate the time-dependent discharges being received through the Northern, Southern, Eastern and Western faces of the ditches; naming these discharges as $Q_{N}, Q_{S}, Q_{E}$ and $Q_{W}$, respectively, their expressions, thus, can be represented as

$$
\begin{gathered}
Q_{N}(t)=-K_{y} \int_{0}^{h} \int_{0}^{L}\left(\frac{\partial \phi}{\partial y}\right)_{y=B} d x d z, \\
Q_{S}(t)=K_{y} \int_{0}^{h} \int_{0}^{L}\left(\frac{\partial \phi}{\partial y}\right)_{y=0} d x d z,
\end{gathered}
$$

$$
Q_{E}(t)=-K_{x} \int_{0}^{h} \int_{0}^{B}\left(\frac{\partial \phi}{\partial y}\right)_{x=L} d y d z
$$

and

$$
Q_{W}(t)=K_{x} \int_{0}^{h} \int_{0}^{B}\left(\frac{\partial \phi}{\partial y}\right)_{x=0} d y d z .
$$

Further, by performing time integrals on the concerned discharges functions, the volume of water seeping through the top and vertical faces of the studied ponded system within a desired time interval can also be worked out.

\section{References}

[1] Hoorn Van J W and Alphen Van J G 1994 Salinity control. In: Ritzema H P (Ed.) Drainage principles and applications. ILRI 533-600. Wageningen: ILRI 
[2] Ritzema H P, Satyanarayana T V, Raman S and Boonstra J 2008 Subsurface drainage to combat water logging and salinity in irrigated lands in India: lessons learned in farmer's field. Agric. Water Manage. 95: 179-189

[3] Youngs E G 1994 Seepage to ditches from a ponded surface. J. Hydrol. 161: 145-154

[4] Smedema L K, Abdel-Dayem S and Ochs W J 2000 Drainage and agricultural development. Irrig. Drain. Syst. 14: 223-235

[5] Wichelns D, Cone D and Stuhr G 2002 Evaluating the impact of irrigation and drainage policies on agricultural sustainability. Irrig. Drain. Syst. 16: 1-14

[6] Ghassemi F, Jakeman A J and Nix H A 1995 Salinisation of land and water resource: human causes, extent, management and case studies. Sydney: University of New South Wales Press

[7] Khan S, Tariq R, Yuanlai C and Blackwell J 2004 Can irrigation be sustainable? In: New directions for a diverse planet: Proceedings of the 4th International Crop Science Congress 2004, Brisbane, Australia, 26 September-1 October 2004.

[8] Martinez-Beltran J 2002 World food summit. Food and Agriculture Organization of the United Nations (http: //www. fao.org /worldfoodsummit /english/ newsroom/focus/focus1.htm)

[9] Rhoades J D 1997 Sustainability of irrigation: an overview of salinity problems and control strategies. In: Proceedings of the 1997 Annual Conference of the Canadian Water Resources Association, Footprints of Humanity: Reflections on Fifty Years of Water Resources Developments, Lethbridge, Alberta, Canada, June 3-6, 1997

[10] Barua G and Alam W 2013 An analytical solution for predicting transient seepage into ditch drains from a ponded field. Adv. Water Resour. 52: 78-92

[11] Rao K V G K and Leeds-Harrison P B 1991 Desalination with subsurface drainage. Agric. Water Manage. 19: 303-311

[12] Sarmah R and Barua G 2015 Hydraulics of a partially penetrating ditch drainage system in a layered soil receiving water from a ponded field. J. Irrig. Drain. Eng. 141: 04015001

[13] Xin P, Yu X, Lu C and Li L 2016 Effects of macro-pores on water flow in coastal subsurface drainage systems. Adv. Water Resour. 87: 56-67

[14] Youngs E G and Leeds-Harrison R B 2000 Improving efficiency of desalinization with subsurface drainage. J. Irrig. Drain. Eng. 126(6): 375-380

[15] Groenigen K J V, Kessel C V and Hungate B A 2013 Increased greenhouse-gas intensity of rice production under future atmospheric conditions. Nat. Clim. Chang. 3: 288-291

[16] Qiu J 2009 China cuts methane emissions from rice fields. Nature News, doi:10.1038/news.2009.833

[17] Brainard E C and Gelhar L W 1991 Influence of vertical flow on ground-water transport. Ground Water 29(5): 693-701

[18] Kirkham D 1950 Seepage into ditches in the case of a plane water table and an impervious substratum. Trans. Am. Geophys. Union 31(3): 425-430

[19] Kirkham D 1960 Seepage into ditches in the case of a plane water table overlying a gravel substratum. Trans. Am. Geophys. Union 65(4): 1267-1272

[20] Kirkham D 1965 Seepage of leaching water into drainage ditches of unequal water level height. J. Hydrol. 3: 207-224
[21] Kirkham D, Toksoz S and Van der Ploeg R R 1974 Steady flow to drains and wells. Drainage for Agriculture. USA: American Society of Agronomy

[22] Fukuda H 1975 Underdrainage into ditches in soil overlying an impervious substratum. Trans. Am. Geophys. Union 38(5): 730-739

[23] Barua G and Tiwari K N 1995 Analytical solutions of seepage into ditches from ponded fields. J. Irrig. Drain. Eng. 121(6): 396-404

[24] Bereslavskii E N 2006 Groundwater flow to a system of drainage canals. Water Resour. 33(4): 417-420

[25] Ilyinsky N B and Kacimov A R 1992 Problems of seepage to empty ditch and drain. Water Resour. Res. 28(3): 871-877

[26] Römkens M J M 2009 Estimating seepage and hydraulic potentials near incised ditches in a homogeneous, isotropic aquifer. Earth Surf. Process. Landf. 34: 1903-1914

[27] Warrick A W and Kirkham D 1969 Two-dimensional seepage of ponded water to full ditch drains. Water Resour. Res. 5(3): 685-693

[28] Afruzi A, Nazemi A H and Sadraddini A A 2014 Steadystate subsurface drainage of ponded fields by rectangular ditch drains. Irrig. Drain. 63(5): 668-681

[29] Barua G and Sarmah R 2016 An analytical solution for predicting transient seepage into partially penetrating ditch drains receiving water from a ponded field. Acta Geophys. 64(1): 149-205

[30] Chahar B R and Vadodaria G P 2008 Steady subsurface drainage of homogeneous soil by ditches. Water Manage. 161(WM6): 303-311 (Proceedings of ICE)

[31] Chahar B R and Vadodaria G P 2008 Drainage of ponded surface by an array of ditches. J. Irrig. Drain. Eng. 134(6): $815-823$

[32] Chahar B R and Vadodaria G P 2012 Steady subsurface drainage of ponded surface by an array of parallel ditches. $J$. Hydrol. Eng. 17(8): 895-908

[33] Voss C I and Provost A M 2008 SUTRA: a model for saturated-unsaturated variable-density ground-water flow with solute or energy transport. U.S. Geological Survey WaterResources Investigations Report 02-4231

[34] Dielman P J 1973 Reclamation of salt-affected soils in Iraq. Publication No. 11, Wageningen, The Netherlands: International Institute for Land Reclamation and Improvement

[35] Martinez-Beltran J 1978 Drainage and reclamation of salt affected soils in the Bardenas area, Spain. ILRI Publication 24. Wageningen, The Netherlands: ILRI

[36] Mirjat M S and Rose D A 2009 Streamline pattern and salt leaching through progressive flooding between subsurface drains. Irrig. Drain. 58: 199-208

[37] Murdoch L C 1994 Transient analysis of an interceptor trench. Water Resour. Res. 30(11): 3023-3031

[38] Meigs L C and Bahr J M 1995 Three-dimensional groundwater flow near narrow surface water bodies. Water Resour. Res. 31(12): 3299-3307

[39] Hossain M and Narciso J 2004 Long-term prospects for the global rice economy. In: Proceedings of FAO Rice Conference, Rome, Italy

[40] Hantush M S 1964 Hydraulics of well. In: Chow V T (Ed.) Advances in hydroscience. New York: Academic Press pp. 281-442

[41] Kirkham D and Powers W L 1972 Advanced soil physics. Wiley-Interscience, New York 
[42] Sarmah R 2015 Two-and three-dimensional analysis of flow into ditch drains from a ponded field. Ph.D. Thesis, Indian Institute of Technology Guwahati, India (thesis accepted)

[43] Grove D B, Beatam W A and Sower F B 1970 Fluid travel time between a recharging well pair in an aquifer having a uniform regional flow field. Water Resour. Res. 6(5): 1404-1410

[44] Hultquist J P M 1992 Constructing stream surfaces in steady 3D vector fields. In: Proceedings of Visualization'92, pp. 171-198

[45] Steward D R 1998 Stream surfaces in two-dimensional and three-dimensional divergence-free flows. Water Resour. Res. 34(5): 1345-1350

[46] Chiang W and Kinzelbach W 2001 3D-groundwater modeling with PMWIN: a simulation system for modeling groundwater flow and pollution. Berlin: Springer-Verlag

[47] Maasland M 1957 Soil anisotropy and land drainage. In: Luthin J N (Ed.) Drainage of agricultural lands. Madison, Wisconsin: American Society of Agronomy, pp. 216-285

[48] Schafer D C 1996 Determining capture zones in homogeneous anisotropic aquifers. Ground Water 34(4): 628-639

[49] Chen S K and Liu C W 2002 Analysis of water movement in paddy rice fields (I) experimental studies. J. Hydrol. 260: 206-215

[50] MacDonald A M, Bonsor H C, Dochartaigh B E O and Taylor R G 2012 Quantitative maps of groundwater resources in Africa. Environ. Res. Lett. 7(2): 024009

[51] Stibinger J 2009 Terrain experimental measurement of saturated hydraulic conductivity on paddy fields in Taoyuan
(Taiwan) during the cycle of flooded period. Agric. Trop. Subtrop. 42(2): 82-89

[52] Tabuchi T 2004 Improvement of paddy field drainage for mechanization. Paddy Water Environ. 2: 5-10

[53] Chen C S and Chang C C 2003 Well hydraulics theory and data analysis of the constant head test in an unconfined aquifer with the skin effect. Water Resour. Res. 39(5): 1121

[54] Grisak G E and Cherry J A 1975 Hydrologic characteristics and response of fractured till and clay confining a shallow aquifer. Can. Geotech. J. 12(1): 23-43

[55] Neuman S P 1975 Analysis of pumping test data from anisotropic unconfined aquifers considering delayed gravity response. Water Resour. Res. 11(2): 329-342

[56] Sharp J M 1984 Hydrogeologic characteristics of shallow glacial drift aquifers in dissected till plains (North-Central Missouri). Ground Water 22: 683-689

[57] Shaver R B 1998 The determination of glacial till specific storage in north Dakota. Ground Water 36: 552-557

[58] Lundstrom D R and Stegman E C 1988 Irrigation scheduling by the checkbook method. Bulletin AE-792 (Rev.), North Dakota State University Extension Service, Fargo

[59] Ayars J E, Corwin D L and Hoffman G J 2012 Leaching and root zone salinity control. In: Wallender W W and Tanji K K (Eds.) Agricultural salinity assessment and management, 2nd ed., ASCE Manual and Reports on Engineering Practice No. 71. Reston, VA: ASCE. Chapter 12, pp. 371-403

[60] FAO 1985 Water quality for agriculture. Irrigation and Drainage, Paper 29, Rev. 1. Rome: FAO 